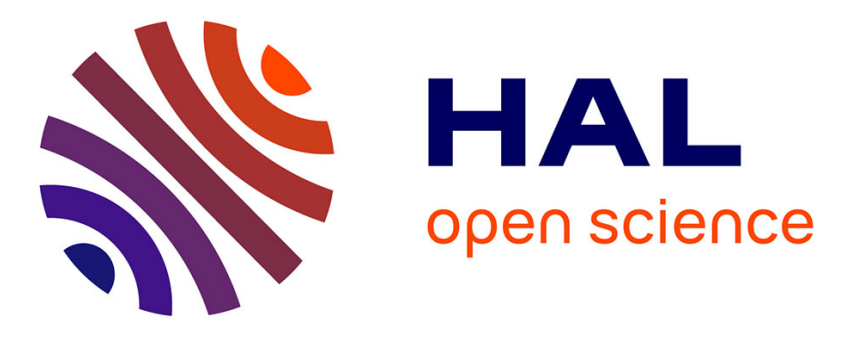

\title{
The Rac1 splice form Rac1b favors mouse colonic mucosa regeneration and contributes to intestinal cancer progression
}

Larissa Kotelevets, Francine Walker, Godefroy Mamadou, Thérèse Lehy, Peter Jordan, Eric Chastre

\section{To cite this version:}

Larissa Kotelevets, Francine Walker, Godefroy Mamadou, Thérèse Lehy, Peter Jordan, et al.. The Rac1 splice form Rac1b favors mouse colonic mucosa regeneration and contributes to intestinal cancer progression. Oncogene, 2018, 37 (46), pp.6054-6068. 10.1038/s41388-018-0389-7 . hal-03071333

\section{HAL Id: hal-03071333 \\ https://hal.sorbonne-universite.fr/hal-03071333}

Submitted on 16 Dec 2020

HAL is a multi-disciplinary open access archive for the deposit and dissemination of scientific research documents, whether they are published or not. The documents may come from teaching and research institutions in France or abroad, or from public or private research centers.
L'archive ouverte pluridisciplinaire HAL, est destinée au dépôt et à la diffusion de documents scientifiques de niveau recherche, publiés ou non, émanant des établissements d'enseignement et de recherche français ou étrangers, des laboratoires publics ou privés. 
The Rac1 splice form Rac1b favors mouse colonic mucosa regeneration and contributes to intestinal cancer progression

Larissa Kotelevets ${ }^{1,2^{*}}$, Francine Walker ${ }^{3,4}$, Godefroy Mamadou ${ }^{5}$, Thérèse Lehy ${ }^{3}$, Peter Jordan 6 , Eric Chastre ${ }^{1,2^{\star}}$

1 Institut National de la Santé et de la Recherche Médicale, UMR S 938, Centre de Recherche Saint-Antoine, Paris, France;

2 Université Pierre-et-Marie-Curie Paris 6, Hôpital Saint-Antoine, Site Bâtiment Kourilsky, Paris, France

3 Institut National de la Santé et de la Recherche Médicale, U1149, Centre National de la Recherche Scientifique-ERL8252, Centre de Recherche sur I'Inflammation, Paris, France;

${ }^{4}$ Assistance publique-Hôpitaux de Paris, Hôpitaux Universitaires Paris Nord Val de Seine Bichat-Claude Bernard, Department of Pathology, Paris, France

${ }^{5}$ TransCell-Lab Laboratory, Faculty of Medicine Xavier Bichat, University of Paris Diderot - Paris7, Paris, France

${ }^{6}$ Department of Human Genetics, National Health Institute, Doctor Ricardo Jorge, Lisbon, Portugal

Running title: Rac1b in colitis and intestinal tumorigenesis 
${ }^{*}$ Corresponding authors:

Eric Chastre, PhD

Larissa Kotelevets, PhD

Cancer biology and therapeutics

Centre de Recherche Saint-Antoine

Inserm UMR S 938, Université Pierre-et-Marie-Curie Paris 6,

Hôpital Saint-Antoine, Site Bâtiment Kourilsky

34 rue Crozatier,

75012 Paris, France

e-mails:eric.chastre@inserm.fr ; larissa.kotelevets@inserm.fr

Tel: +33 (0)157 277470

Fax: +33 (0)157 277471

Word count (excluding abstract, references and figure legends): 4932 


\section{Abstract}

We previously have identified the ectopic expression of Rac $1 \mathrm{~b}$, an activated and novel splice variant of Rac1 in a subset of human colorectal adenocarcinomas, as well as, in inflammatory bowel diseases and in colitis mouse model. Rac1b overexpression has been further evidenced in breast, pancreatic, thyroid, ovarian and lung cancers. In this context, the aim of our study was to investigate the physiopathological implications of Rac1b in intestinal inflammation and carcinogenesis in vivo.

The ectopic expression of Rac1b was induced in mouse intestinal epithelial cells after crossing Rosa26-LSL-Rac1b and villin-Cre mice. These animals were let aging or were challenged with dextran sulfate sodium (DSS) to induce experimental colitis, or either received azoxymethane $(\mathrm{AOM}) / \mathrm{DSS}$ treatment, or were bred with $\mathrm{Apc}^{\mathrm{Min} /+}$ or II10-- mice to trigger intestinal tumors.

Rac1b ectopic expression increased intestinal epithelial cell proliferation and migration, enhanced production of reactive oxygen species, and promoted the Paneth cell lineage. Although Rac1b overexpression alone was not sufficient to drive intestinal neopasia, it enhanced Apc-dependent intestinal tumorigenesis. In the context of II10 knockout, the Rac1b transgene strengthened colonic inflammation due to induced intestinal mucosa permeability and promoted cecum and proximal colon carcinogenesis. In contrast, Rac1b alleviated carcinogen/ acute inflammationassociated colon carcinogenesis (AOM/DSS). This resulted, at least partly from the early mucosal repair after resolution of inflammation. Our data highlights the critical role of Rac1b in driving wound-healing after resolution of intestinal inflammation, and in cooperating with Wnt pathway dysregulation and chronic inflammation to promote intestinal carcinogenesis. 
Keywords : colorectal cancer; inflammation; Rac1b; mouse model; Apc; colitis 


\section{Introduction}

Colorectal cancer arises from the stepwise accumulation of genetic and epigenetic alterations, including the activation/overexpression of a series of (proto)-oncogenes, and the inactivation of tumor suppressor genes ${ }^{1,2}$. The incidence of KRAS activation led us to evaluate the implication of other small GTPases and to identify a novel splice variant of Rac1 overexpressed in human colonic tumors that we designed Rac1b3

Rac1b variant results from inclusion of exon $3 b$, which leads to a 19-amino acid inframe insertion immediately C-terminal to the switch II domain. The balance in Rac1/ Rac1b levels is regulated by splicing factors, that either induce skipping of the alternative exon $3 b$ or favor its inclusion 4,5 .

Comparative to Rac1, Rac1b exhibits a number of distinctive features. This variant is preferentially in a GTP-bound active form, due to its reduced intrinsic GTPase activity and its impaired binding to Rho-GDI6. Unlike Rac1, Rac1b does not activate PAK1, AKT1, c-Jun-NH2-kinase nor the transactivation activity of RelB-NF-kappaB2/p1007,8. On the other hand, the extra 19-amino acid sequence enhances Rac1b binding to SmgGDS, RACK1 and p120 catenin, proteins involved in cell-cell adhesion, motility, and transcriptional regulation ${ }^{9}$. Rac1b also exacerbates the cellular production of reactive oxygen species (ROS) ${ }^{10,11}$.

Several lines of evidence suggest a role for Rac1b in the neoplastic progression. RAC1b overexpression is associated with colorectal cancers with BRAF mutation, which in advanced stage are characterized by a bad prognosis ${ }^{12}$. Likewise, Rac1b overexpression is associated with a poor outcome of patients with wild-type KRAS/ BRAF metastatic colorectal cancer treated with FOLFOX/XELOX chemotherapy ${ }^{13}$. Besides colon cancer, the ectopic expression of Rac1b has been evidenced in 
breast, thyroid, ovarian, pancreatic and lung cancers ${ }^{14-20}$. It is noteworthy that activating Rac1 mutations have been identified in melanomas, as well as in prostate, head and neck, and testicular cancers, and that Rac1 was found overexpressed in lung and breast cancers 21 . Experimental studies revealed that Rac1b increased G1/S progression and survival of NIH3T3 cells, and was sufficient to induce the transformation of these mouse fibroblasts 22,23 . Rac1b might also be involved in later stages of carcinogenesis. Accordingly, Rac1b has been reported to mediate epithelial-mesenchymal transition (EMT) in mouse mammary epithelial cells, via ROS production and the accumulation of the transcription factor Snail 24 . ROS acts as signaling molecules through protein oxidation, e.g. phosphatase inactivation, but also causes oxidative damage and induces genomic instability, stimulating carcinogenesis. Nevertheless, whether Rac1b is directly involved in the initiation or in the progression of colon cancer, or is just a passenger splice variant has not been investigated so far.

On the other hand, we have also recently demonstrated that Rac1b was expressed in human inflammatory colonic mucosa, as well as in experimental mouse models of colitis $^{25}$. The connection between inflammation and carcinogenesis led us, in the present study, to delineate in an integrated manner, the pathophysiological significance of Rac1b in these two processes. We targeted the Rac1b ectopic expression in vivo to mouse intestinal epithelial cells, and we investigated the development of colitis and/or tumors, i) spontaneously; ii) following challenge with dextran sulfate sodium (DSS) to induce experimental colitis, or iii) after either azoxymethane (AOM)/DSS treatment, or breeding with $\mathrm{Apc}^{\mathrm{Min} /+}$ or II10-/- mice to drive intestinal tumors. 


\section{Results}

\section{Breeding and phenotyping villin-Cre LSL-Rac1b mice}

Crossing Rosa26-LSL-Rac1 $b^{\text {floxflox }}$ and villin-Cre ${ }^{+/-}$animals generated the villin-Cre+/Rosa26-LSL-Rac1bflox/- mice. These mice were then backcrossed with Rosa26-LSLRac1bfloxflox to produce villin-Cre ${ }^{+/-}$Rosa26-LSL-Rac1bfloxflox mice (referred to as villin-Cre LSL-Rac1bfloxflox mice). The expression of Rac1b along the small intestine and the colon was evaluated by RT-qPCR (Figure 1A). In heterozygous villin-Cre LSL-Rac1 $b^{\text {floxl- }}$ and homozygous villin-Cre LSL-Rac1 $b^{\text {floxfllox }}$ mice, Rac1b expression represented 6-16-fold and 9-26-fold the endogenous levels measured in the matched segments from the Cre-negative control group (LSL-Rac1bfloxflox mice, referred as wild-type), respectively. When Rac1b mRNA levels were measured relative to total Rac1 transcripts, they corresponded to $0.5-2 \%$ of total Rac1 in intestine from control mice, $4-7.6 \%$ in villin-Cre LSL-Rac1 1 flox/- mice and $7.5-15.8 \%$ in villin-Cre LSLRac1bfloxflox animals (Figure 1A). This overexpression of Rac1b transcripts is in the range of the 1.9-4.1 fold increase reported in human colorectal tumors compared with control mucosa ${ }^{12}$. Rac1b protein was barely detected in colonic mucosa of wild-type mice, in line with the low level of the splice variant reported in rat colonic epithelium 26. The relative accumulation of Rac1b was twice as high in the intestinal mucosa of homozygous villin-Cre LSL-Rac1 bfloxflox mice as compared with heterozygous mice (Figure 1A).

We did not notice any variation in the average lifespan in the control and the transgenic mice. To delineate the role of Rac $1 b$ in the initiation of colorectal carcinogenesis, three groups of animals, 12 control mice, 13 villin-Cre LSL-Rac $1 b^{\text {flox/- }}$

mice and 20 villin-Cre LSL-Rac1bfloxflox mice were sacrified when aged over 18 months. The macroscopic and the histological examination of the intestinal mucosa 
of villin-Cre Rac $1 b^{\text {floxfllox }}$ mice did not reveal any morphological alteration or any tumor (Figure 1B). The architecture of the mucosa was similar to that of control group. These observations indicate that Rac1b overexpression alone was unable to trigger intestinal carcinogenesis.

Nevertheless, Rac1b proved to be functionally expressed since the steady state level of ROS was enhanced in colonic mucosa of villin-Cre Rac1bfloxflox mice (Figure 1C). Furthermore, Rac1b overexpression was associated with an increase in the number of Paneth cells in the bottom of ileal crypts, as well as in the accumulation of the cryptdin transcripts that are selectively expressed by this cell lineage (Figure 1D).

We further investigated expression and subcellular localization of $\beta$-catenin, which is involved in adherens junctions, cell proliferation and tissular homeostasis. We evidenced an increased number of $\beta$-catenin nuclear-positive cells in the bottom of intestinal crypts from villin-Cre LSL-Rac1bfloxflox mice as compared to control (Figure 1E).

\section{Rac1b stimulates both proliferation and motility of intestinal epithelial cells}

Since ROS and $\beta$-catenin are known to promote cell proliferation, we further investigated the effect of Rac1b ectopic expression on intestinal epithelial cell renewal. Cell proliferation was analyzed in vivo using immunostaining of KI67 -a nuclear protein present in all phases of the cell cycle, except G0-, and BrdU -a thymidine analog that incorporated into the newly synthesized DNA (S phase) of replicating cells-. As shown in Figure 2A and B, Rac1b expression was associated with a significant increase in the proliferative index of colonic epithelial cells, from $36.5 \%$ to $52 \%$ for $\mathrm{KI} 67$, and from $10.5 \%$ to $16.5 \%$ for $\mathrm{BrdU}$. The increase in cell proliferation was not associated with any change in the spatial distribution of labeled 
cells, and the number of cells per hemicrypt and the crypt depth were similar in both groups of animals (Figure 2C).

The relative accumulation of Lgr5 transcripts -a stem cell marker- in epithelial cells isolated from jejunum, ileum and colon was similar in villin-Cre LSL-Rac1 $1 b^{\text {flox/flox }}$ and wild-type mice (Supplementary Figure 1A-C). In agreement with the knowledge of the localization of stem cells at the bottom of the crypts, Lgr5 mRNA levels were 4fold higher in bottom compared with the top of colonic crypts (Supplementary Figure 1A). The relative accumulation of cyclin D1 transcripts was similar in the bottom fraction of Rac1b transgenic and wild-type mice. However, in line with the extended proliferative area evidenced by KI67 immunostaining, the level of cyclin D1 transcripts in the top fraction was significantly higher in Rac1b transgenic mice as compared to control animals. This increased cyclin D1 accumulation was also evidenced in ileum, but this trend was not significant in jejunum, probably due to the higher villi height in this segment and to the dilution of progenitors cells with mature enterocytes (Supplementary Figure 1B and C).

The absence of mucosal hyperplasia related to the sustained cell proliferation implied either an increase in cell motility or an enhanced apoptosis. Detection of apoptosis by TUNEL assay did not reveal any marked change in nuclear DNA fragmentation in intestinal and colonic epithelial cells from villin-Cre LSL-Rac1bflox/flox under physiological conditions (Supplementary Figure 2). To evaluate migration of small intestinal enterocytes in vivo we used the BrdU-assay27. Twenty hours after BrdU injection, the uppermost BrdU epithelial positive cells (cellmax) in the small intestinal mucosa of villin-Cre ${ }^{+/}$Rac1 $b^{\text {flox/flox }}$ mice were found in significantly higher positions than measured for the controls (166 $\pm 19 \mu \mathrm{m}$ vs. $116 \pm 8 \mu \mathrm{m}$, respectively) (Figure 2D). This enhanced cell migration along the crypt-villus axis was not associated with any 
change in villus length, indicating that the balance between proliferation, on the one hand, and cell migration, on the other, were preserved in Rac1b transgenic mice.

\section{Rac1b favors recovery after DSS -induced colitis}

To address the implication of Rac1b during the acute inflammatory process, control, villin-Cre LSL-Rac1 $b_{\text {floxl- }}$ and villin-Cre LSL-Rac1bfloxflox mice were challenged with 3\% DSS for 5 days, followed by 2 days of recovery. As shown in Figure $\mathbf{3 A}$ and $\mathbf{B}$, the decrease in body weight became apparent after 4 days of treatment, continued even 2 days after DSS administration, and was superimposable in the 3 groups of animals. The clinical index taking into account weight loss, stool consistency and rectal bleeding was identical in control and villin-Cre LSL-Rac1bflox/lox mice (Figure 3B). An additional indicator of disease severity in colitis is colon shortening. As shown in Figure $\mathbf{3 C}$, the changes in colon length after DSS treatment were comparable in the 3 experimental groups. Furthermore, histological analysis revealed that the extent of the colonic mucosal injury and tissue regeneration were similar in the wild-type and in villin-Cre LSL-Rac1 bflox/flox mice (Figure 3D).

Subsequently, we further characterized the impact of Rac1b ectopic expression on the resolution phase of colitis. For this purpose, mice were allowed to recover for 7 days after the end of the DSS treatment. Kaplan-Meier curves revealed a significant decreased survival of wild-type mice compared with Rac1b transgenic mice (Figure 3E). On day 9 , more than $25 \%$ control mice have died as compared to less than $10 \%$ villin-Cre LSL-Rac1 bfloxfllox mice, whereas on day 12 , only $54 \%$ control mice remained vs. $79 \%$ villin-Cre LSL-Rac1bfloxflox. This higher mortality of wild-type mice was related to the sustained weight loss (up to day 9) and the delayed resolution of colitis (Figure 3F). In this context, histological analysis revealed a faster mucosal repair in villin-Cre LSL-Rac1 bfloxfllox mice, representing $78 \pm 5 \%$ of the initial lesions length vs. 
$50 \pm 8 \%$ in control mice, the remaining lesions being $3.1 \pm 0.8 \%$ and $17.0 \pm 4 \%$, respectively (Figure 3G). This tissue repair was characterized by areas of thin regenerative epithelial monolayers and by hyperplastic foci (Figure $\mathbf{3 H}$ ). The increased epithelial intestinal cell proliferation and migration evidenced under physiological conditions in villin-Cre LSL-Rac1 1 floxfflox mice might contribute to the gain in colonic tissue regeneration after resolution of inflammation.

Intestinal wound healing is a multistep process dependent on the precise balance of migration, proliferation, and differentiation of the epithelial cells adjacent to the wounded area, and the interplay with stromal and immune cells. Induction of several inflammatory cytokines was evidenced at mRNA and protein levels during the acute and the resolution phases of inflammation (Supplementary Figures 3 and 4). The evaluation of immune cell infltrates and of the transcripts encoding cytokines in distal colon demonstrated a faster normalization in villin-Cre LSL-Rac1bfloxflox mice as compared to wild-type mice (Supplementary Results and Supplementary Figure 3).

In addition, DSS treatment markedly increased the number of phosphorylated histone $\mathrm{H} 2 \mathrm{AX}(\gamma \mathrm{H} 2 \mathrm{AX})$-positive cells -a biomarker of DNA damage and repair- in the colonic mucosa of Rac1b trangenic mice, as compared to wild-type mice (Supplementary Figure 5). Nevertheless, TUNEL assay did not allow to evidence any variation of apoptosis in the two groups of animals (Supplementary Figure 6).

\section{Impact of Rac1b overexpression on azoxymethane (AOM)/ DSS -induced colon carcinogenesis}

Since Rac1b overexpression was not sufficient to drive intestinal carcinogenesis, we challenged control and villin-Cre LSL-Rac1 $b^{\text {floxflox }}$ mice with carcinogen (AOM)/ acute inflammation (DSS)-associated colon carcinogenesis. Control and villin-Cre LSL- 
Rac1bfloxflox mice received two injections of azoxymethan and were subsequently subjected to DSS-induced colitis (Figure 4A). Eight weeks after the first injection, mice have developed a diffuse carcinogenesis in the distal colon (Figure 4A). The quantitation of the number of tumors by microscopic examination, and the measure of tumor areas indicated that Rac1b curbed AOM-DSS-induced carcinogenesis, the average number of tumors and total area being $14.9 \pm 1.7$ and $62.2 \pm 8.5 \mathrm{~mm}^{2}$ for wildtype mice, and $9.9 \pm 1.1$ and $38.5 \pm 5.1 \mathrm{~mm}^{2}$ for villin-Cre LSL-Rac1 $\mathrm{b}^{\text {floxfllox }}$ mice, respectively (Figure 4B and C). The different susceptibility of wild-type and Rac1b transgenic mice to AOM/DSS -induced carcinogenesis was not related to marked variation in apoptosis profile, as evaluated at the time of sacrifice (Supplementary Figure 7).

In this experimental model, the induction of colon carcinogenesis was clearly dependent on DSS-induced inflammation. This was evidenced by the correlation between the body weight loss -reflecting the extent of colitis-, and tumor areas or tumor number at the time of sacrifice (Figure 4D). Thus, the faster tissue repair and the early normalization of inflammatory cytokines levels may explain the lower sensitivity of villin-Cre LSL-Rac1bfloxflox mice to carcinogen/ acute inflammationassociated colon carcinogenesis (AOM/DSS).

\section{Cooperation between of Rac1b overexpression and Apc or Il10 inactivation in intestinal carcinogenesis}

Colorectal cancer involves the dysregulation of a series of signaling pathways, including the stimulation of $\mathrm{Wnt} / \beta$-catenin pathway through inactivation of the APC tumor suppressor gene. The Apc ${ }^{\mathrm{Min} /+}$ mice bear a heterozygous nonsense mutation of the $A p c$ gene and develop numerous adenomas/carcinomas in the small intestine 
and in the colon ${ }^{28}$. The molecular analysis of these tumors revealed high levels of the transcripts encoding the proinflammatory cytokine CXCL2 $(7.9 \pm 1.8$-fold and $53 \pm 17$ fold increase in small intestinal and colonic tumors, as compared with adjacent control mucosa). Interestingly, we observed also an increase in Rac1b mRNA $(1.9 \pm 0.1$-fold in intestinal tumors; $2.2 \pm 0.5$-fold in colonic tumors, Figure $5 \mathbf{A})$. This increase in Rac1b expression did not result in the overrepresentation of epithelial cells in tumors, since cytokeratin-8 levels were in the same range in the tumor and adjacent control mucosa (Figure 5A).

Since these results suggested an interplay between $\mathrm{Wnt} / \mathrm{Apc} / \beta$-catenin pathway and Rac1b during colorectal carcinogenesis, we crossed villin-Cre LSL-Rac1bfloxflox mice with $\mathrm{Apc}^{\mathrm{Min} /+}$ mice. As shown in Figure 5B, tumor size and tumor distribution along the small intestine were similar in villin-Cre LSL-Rac1 $\mathrm{b}^{\text {floxl- }} \mathrm{Apc} \mathrm{Min}^{\mathrm{M}}$ mice and in $\mathrm{Apc} \mathrm{Min}^{\mathrm{in}}$ + mice. The highest number of tumors was observed in the duodenum and the ileum. In contrast, we evidenced that Rac1b ectopic expression increased by $33 \%$ tumor burden in the small intestine and a 4-fold increase in average tumor number in the colon of bi-mutant animals (Figure 5C).

We attempted to produce cohorts of villlin-Cre LSL-Rac1 $\mathrm{b}^{\text {flox/flox }} \mathrm{Apc} \mathrm{Min} /+^{\mathrm{i}}$ mice. We generated 3 mice with this genotype, all of them died before the age of 16 weeks. Although we could not perform any histological or biological analysis of these animals, these observations suggest a dose-effect of Rac1b ectopic expression in its cooperation with $\mathrm{Wnt} / \mathrm{Apc} / \beta$-catenin pathway to promote intestinal carcinogenesis.

We further investigated the implication of Rac1b in chronic inflammation-associated colorectal cancer. Mice deficient in the II10 anti-inflammatory cytokine spontaneously develop a chronic inflammatory bowel disease that can manifest as rectal prolapses, 
and are characterized by a 250 fold increase in CXCL-2/MIP2 $\alpha$ mRNA accumulation and a 2.7-fold rise in Rac1b mRNA accumulation (Supplementary Figure 8).

As shown in Figure 6A, the ectopic expression of Rac1b in II10 knockout mice aged 16 weeks increased the incidence of cecal and proximal colon adenocacinomas (from $7.5 \%$ to $78 \%$ for cecum, $32.5 \%$ to $78 \%$ for proximal colon), characterized by a mucinous phenotype. The evaluation of the accumulation of the transcripts encoding inflammatory cytokines revealed higher levels of IFN- $y$, TNF- $\alpha$ and CXCL2/MIP2 $\alpha$ in the proximal and distal colon from II10-/- mice as compared to wild-type and villin-Cre LSL-Rac1 $\mathrm{b}^{\text {floxfflox }}$ mice. In these two later lines of animals, the relative accumulation of cytokine transcripts was similar. Nevertheless, IFN- $\gamma$ and TNF- $\alpha$ mRNA levels tended to be higher in the proximal colon as compared to distal colon. Interestingly, although Rac1b ectopic expression per se did not increase proinflammatory cytokine mRNA levels, in the context of II10 deficiency Rac1b potentiated the accumulation of IFN- $\gamma$, TNF- $\alpha$, II6, TGF- $\beta$ and CXCL2/MIP2 $\alpha$ in the proximal colon of villin-Cre LSL-Rac1bflox/ flox II10-/- mice (Figure 6B). These observations led us to hypothesize that Rac1b might alter the intestinal barrier function. As shown in Figure 6C, the conductance of the proximal colon measured using Ussing chambers was significantly higher in Rac1b transgenic mice as compared to control $\left(11.1 \pm 0.8\right.$ vs $\left.4.8 \pm 0.5 \mathrm{mS} / \mathrm{cm}^{2}\right)$. This indicates an increased colonic paracellular permeability in villin-Cre LSL-Rac1 bfloxfllox mice compared to wild-type animals.

Thus, increased intestinal permeability in the context of an hyperactive immune response might account for the exacerbation and chronicity of colonic inflammation and the subsequent tumor development in villin-Cre LSL-Rac1 $\mathrm{b}^{\text {flox/flox }} \| 10^{-/}$mice, associated with a marked decrease in overall survival (Figure 6D). 


\section{Discussion}

Our manuscript provides the first in vivo investigation on the role of Rac1b ectopic expression in the initiation and the progression of intestinal cancers and in the development of colitis.

The ectopic expression of Rac1b has been reported in various human malignancies. We demonstrated here that this overexpression was unable to initiate intestinal carcinogenesis in mice. Accordingly, we could not evidence any tumor, any aberrant crypt foci or any architectural alteration of the intestinal mucosa in Rac1b transgenic mice aged over one year. In agreement with these findings, Zhou et al showed that Rac1b was unable to trigger lung carcinogenesis in mice ${ }^{20}$. In contrast, Radisky's group reported that Rac1b stimulated lung fibrosis, which evolved to carcinomas ${ }^{19}$. This discrepancy might be related in the later study to the use of FVB strain mice, a genetic background that proved to be more prone to lung cancer ${ }^{29}$.

Nevertheless, if Rac1b was not sufficient to drive neoplastic transformation, we demonstrated that it promotes intestinal epithelial cell proliferation. This enhanced cell proliferation might be related to the Rac1b-induced activation of the $\mathrm{Wnt} / \mathrm{\beta}$ catenin pathways. Accordingly, this pathway is a fundamental cornerstone for intestinal epithelial progenitor cell proliferation ${ }^{30}$. We showed here that Rac1b ectopic expression was associated with the nuclear accumulation of $\beta$-catenin in the bottom of the crypts. In this context, Rac1b has been reported to interact with Dishevelled-3 and form a tetramer with $\beta$-catenin/TCF that is recruited to the promoter of canonical Wnt target genes ${ }^{31,32}$. Here, this could explain that the sustained cell proliferation remained as a continuous area restricted to the basal half of the crypts, due to the short-range Wnt gradient 33 . We also evidenced that Rac $1 \mathrm{~b}$ ectopic expression was associated with the amplification of Paneth cell lineage which is known to produce 
Wnt3. Similarly, a previous study reported that activated Rac1 induces precocious differentiation of members of the Paneth cell in mouse fetal intestine ${ }^{34}$. The requirement of $\mathrm{Wnt} / \beta$-catenin signaling for correct Paneth cell maturation ${ }^{35}$ reveals the fine tuning of this lineage which is tightly involved in the Lgr5+ intestinal stem cell functions ${ }^{36,37}$. The increased in the steady state levels of ROS in colonic mucosa of Rac1b transgenic mice might also contribute to the proliferation of epithelial cells. In this connection Rac1-dependent ROS production was recently reported to mediate intestinal stem cell proliferation in mouse models of colorectal cancer ${ }^{38}$. Furthermore, ROS production by Nox1 in the colonic crypts proved to be required for mucosa repair following DSS-induced colitis ${ }^{39}$.

The Rac1b signaling pathways involved in cell proliferation seems to be dependent on cell type and cellular contexts. Accordingly, Rac1b is required for cell cycle progression of NIH3T3 fibroblasts and Caco-2 colon cancer cells ${ }^{7,22}$. This process is associated with NFkB activation and cyclin D1 accumulation. Rac1b is also required for neurotrophin 3-stimulated proliferation of immature human bone marrow cells, but in this model, the GTPase represses cyclin D1 and cyclin B1 expression ${ }^{40}$. On the other hand, in contrast with Rac1, Rac1b was unable to induce the growth of the human and mouse lung cancer A549 and LKR13 cells, and of the dog kidney epithelial MDCK cell line in 3-D culture20,41.

Analysis of intestinal phenotype related to Rac1b overexpression reveals that the sustained epithelial cell proliferation was not associated with intestinal hyperplasia. The maintenance of intestinal homeostasis might be explained by the increased cell motility. This process might also contribute to the reepithelization of superficial wounds after injury. Accordingly, intestinal wound healing is a multistep process dependent on the precise balance of migration, proliferation, and differentiation of the 
epithelial cells adjacent to the wounded area. First, epithelial cells surrounding the injury lose their columnar polarity, adopt a flattened morphology, and rapidly migrate to restore barrier integrity. Subsequently, proliferation of the mucosal epithelium begins to increase the pool of enterocytes available to resurface the lesions. The induction of $\gamma \mathrm{H} 2 \mathrm{AX}$ in colonic cells of Rac1b transgenic mice during acute inflammation might also contribute to the faster recovery. Rac1 downregulation sensitizes HeLa cells to UV and $\gamma$-irradiation, due to an impair $\gamma \mathrm{H} 2 \mathrm{AX}$ expression and efficient DNA damage response ${ }^{42}$. In this connection, it has been proposed that $\mathrm{yH} 2 \mathrm{AX}$ upregulation in active ulcerative colitis induces cell cycle arrest, allowing repair of DNA damage, whereas its down-regulation leads to undetected DNA damage favoring tumorigenesis ${ }^{43}$.

Althought we have shown that Rac1b by itself was not sufficient to initiate colon carcinogenesis, we demonstrated the impact of Rac1b overexpression on Apc-driven intestinal tumorigenesis. The combination of Apc deficiency with the Rac1b overexpression within epithelial cells results in a dramatic increase in the tumor burden in the small intestine and in the colon of villin-Cre LSL-Rac1floxflox ApcMin/+ mice. This potentiation is consistent with the reinforcement of $\mathrm{Wnt} / \beta$-catenin pathways by Rac1b stated above. Furthermore, this highlights the physiopathological significance of Rac1b accumulation in intestinal tumors of $\mathrm{Apc}^{\mathrm{Min} /+}$ mice. Interestingly, the development of these tumors involves the loss of the wild-type Apc allele, and in intestine is not associated with the induction of oncogene-induced senescence. This contrasts with renal epithelial cells which undergo senescence after Apc loss ${ }^{44}$. Thus, it is likely that Rac1b overexpression provides a proliferative advantage to cancer cells. Whether Rac1b cooperates in vivo with other oncogenic pathways involved in 
colorectal carcinogenesis, such as KRas and BRaf remains an interesting point that could not be addressed here and will require further studies.

Crohn's disease and ulcerative colitis, significantly increases the risk of cancer in patients after prolonged colonic inflammation. These diseases are linked with barrier dysfunction of the epithelial lining cells and an increased in paracellular permeability. Interestingly, although Rac1b increased intestinal permeability, we did not notice any change in the expression of proinflammatory cytokines under physiological conditions. Nevertheless, in the context of chronic intestinal inflammation in II10defective mice, Rac1b sustained-expression exacerbated the inflammatory responses, promoted intestinal carcinogenesis and was associated with a severely reduced life span of compound mutant mice. Thus, Rac1b may promote a low-grade inflammatory process, which is becoming apparent after imbalance of the immune system. Accordingly, TNF- $\alpha$ originating from the mucosa or possibly the epithelium itself, participates in orchestrating the activation of immune cells. TNF- $\alpha$ augments the expression of $\mathrm{CXCL} 1 / \mathrm{KC}$ and $\mathrm{CXCL2/MIP2} \alpha$, which are chemotactic for neutrophils and macrophages. Production of various proinflammatory factors, such as, CXCL1, IFN- $\gamma, \| 6$ by the activated immune system participates in the ensuing inflammatory response but additionally plays a role in tumor growth by providing trophic signals to the early neoplastic lesions. The synergic activity of Rac1b overexpression and II10 depletion in intestinal inflammation might result from an impaired cross-talk between epithelial and immune cells, it might also be related to defective intestinal barrier integrity favoring infiltration of pathogens. Alternatively, it might be linked to dysbiosis, as the result of increased in ROS production, or dysregulation of innate immune response of intestinal epithelial cells (e.g. sensing and response to pathogens and/or commensal bacteria expositions). 
Thus, it is likely that Rac1b exerts differential roles and is involved in different steps in sporadic and colitis-associated colorectal cancers. In sporadic colorectal cancer, Rac1b cooperates with activated pro-oncogenic signaling pathways favoring progression, as suggested by the dose-dependent effect of Rac1b with Apc defficiency. Alternatively, Rac1b might also allow to escape oncogenic senescence ${ }^{12,19}$. In these tumors, the induction of the inflammatory process appears as a consequence of the recruitment of immune cells that follows tumor development.

In the case of colitis-associated colorectal cancer, chronic inflammation that results from continuous cycles of mucosa injury and repair, might trigger Rac1b overexpression which might cooperate in cancer initiation by inducing ROS production within epithelial cells and subsequent mutations and epigenetic silencing of tumor suppressor genes, or by strenghtening inflammation through impaired epithelial barrier function.

In conclusion, our study revealed that depending on cellular and physiological contexts Rac1b might exert protective or pernicious effects (Figure 7). Under physiological condition, Rac1b induces cell proliferation and cell motility, contributes to intestinal homeostasis and tissue repair after injury, on the other hand in the context of cellular oncogenic activation, or dysregulation in the crosstalk between epithelial intestinal, stromal and immune cells, Rac1b might promote neoplastic transformation. The development of complementary experimental models, i.e. knocking out of Rac1 gene exon- $3 \mathrm{~b}^{26}$ and the implementation of mechanistic investigations are required to further delineate the physiopathological role of Rac1b in intestinal inflammation and cancer and to identify and validate therapeutic targets in the context of Rac1b expression. 


\section{Materials and Methods}

\section{Animals}

All experiments were performed in agreement with the European Community Council

Directive of 22nd September 2010 (010/63/UE) and in accordance with a protocol reviewed and approved by the Institutional Animal Care and User Ethical Committee "Comité d'éthique en matière d'expérimentation animale Paris-Nord C2EA 121" of our institution (INSERM and Université Paris Denis Diderot): Approval\#0127.03.

The Rosa26-LSL-Rac1bflox/flox mice (B6;129-Gt(ROSA)26Sortm1(RAC1*)Jkis/J), the C57BI6/J-APCMin/+ and the B6.129P2-II10tm1Cgn mice were purchased from The Jackson Laboratories (Bar Harbor, Maine, USA). The villin-cre (B6-Tg(Vil-cre)20Sy/ Nci) mice were kindly provided by Dr Sylvie Robine (Institut Curie, Paris, France).

Detailed descriptions of animals housing and genotyping are provided in the Supplementary Methods.

\section{Induction of colitis}

Acute colitis was induced by feeding 10-week-old mice with $3 \%$ DSS (36-50 kDa; MP Biomedicals, Illkirch, France) dissolved in drinking water for 5 days, followed by either 2 or 7 days of regular sterile drinking water.

Measurement of the disease activity index is detailed in the Supplementary Methods.

The mice were killed at day 7 or at day 12, and the colon was isolated, opened up, measured in length, examined macroscopically and then sectioned along the anteroposterior axis in order to snap freeze samples of proximal and distal colon for 
biochemical and molecular analyses, the $2^{\text {nd }}$ strech colonic strip being pinned flat on a paraffin wax block and fixed overnight in formalin (Sigma-Aldrich, St Quentin Fallavier, France) for histological quantitations of intestinal lesions and mucosal repair (Supplementary Methods).

\section{Colitis-associated colon cancer}

Azoxymethan (AOM) combined with DSS treatment induces colonic tumors with high penetrance, which mimic human colitis-associated colorectal cancer. Eight-week-old mice received two intraperitoneal injections of azoxymethan (Sigma-Aldrich) at 7.5 $\mathrm{mg} / \mathrm{kg}$ with an interval of one week. One week after the $2^{\text {nd }}$ injection, the mice were exposed for 7 days to $2 \%$ DSS administrated in the drinking water. Eight weeks after the first injection animals were sacrificed, colons were removed and analyzed as described below.

\section{Examination of intestinal mucosa and tumor scoring}

The small intestine of $\mathrm{Apc}^{\mathrm{Min} /+}$ and villin-Cre LSL-Rac1bflox/- APCMin/+ mice was measured and immediately cut into nine equal segments, numbered from the proximal duodenum to the distal ileum. The large intestine was cut into three segments from the cecum to the anal ring. The lumen of segments was filled with formalin solution. After several minutes, these segments were opened, carefully pinned flat on a paraffin wax block to examine the entire mucosa with the minimum of artifact, then fixed overnight in formalin. After fixation, they were measured in length and examined under a light microscope at 40x magnification. The number of adenomas per segment was quantified and their largest diameter measured using a calibrated ocular grid by two independent observers (LK and EC). A similar approach was performed for the quantification of the tumors in AOM/DSS-treated mice, which 
develop tumors mainly in the distal colon. To determine tumor areas in this model for colon cancer, digital high-resolution macroscopic images of the colonic mucosa were captured and analyzed using ImageJ software (National Institutes of Health, Bethesda, MD).

For Histological and immunohistological analysis see Supplementary Methods.

\section{Transepithelial electrical conductance}

Measurement of colon transepithelial electrical conductance was performed using Ussing chambers (Supplementary Methods).

\section{Nucleic acid extractions, reverse transcription and real-time PCR}

Mouse tissues were disrupted using a Polytron apparatus (Kinematica, Thermo Fisher Scientific, Illkirch, France), and RNA was isolated using NucleoSpin RNA II Kit (Macherey-Nagel, Hoerdt, France) and treated with DNAse I to eliminate the contaminating eukaryotic DNA.

For Real-Time $\mathrm{qPCR}$, one microgram of total RNA was reverse transcribed using Moloney murine leukemia virus reverse transcriptase and random primers (Thermo Fisher Scientific). Real-time PCR were conducted in triplicate, using the set of primers listed in the Supplementary Table on a LightCycler 480 Roche QPCR (Roche Diagnostics, Meylan, France). Primers were designed using Roche assay design center or were based on previous studies, and were synthesized by Eurogentec (Angers, France). To determine the relative accumulation of the transcripts in the intestine of control/untreated and transgenic/treated animals, the corresponding threshold cycle (CT) values were first normalized by subtracting the corresponding CT values of S14, which was chosen after multiple comparisons with numerous reference genes and used as the internal standard $(\triangle C T)$. The $\triangle \Delta C T$ 
values were calculated by subtracting the $\Delta C T$ values obtained in the transgenic/ treated and control/ untreated mice and the fold differences in mRNA accumulation in the treated relative to the untreated cells was determined using the formula $2-\Delta \Delta C T$. Statistical analyses were performed on the $\Delta C T$ values.

\section{Statistical Analysis}

All results were expressed as means \pm standard errors of the means (SEM).

The normality of data set was tested statistically using Shapiro-Wilk, Anderson Darling, Lilliefors and Jeque-Bera tests, using XLStat software (Addinsoft, Paris, France). The variance was similar between groups that were being statistically compared.

Differences between controls, transgenic animals and the multiple treatments applied to mice were evaluated by one-way analysis of variance test (ANOVA), followed by Tukey's post hoc test, using XLStat software. When relevant, direct statistical comparisons between two groups were made using unpaired two-tailed t tests. The level of significance was set at $p \leq 0.05$.

\section{Compliance with ethical standards}

Conflicts of interest disclosure:

The authors declared no potential conflict of interest.

\section{Acknowledgements}


The authors acknowledge Dr Sylvie Robine (Institut Curie, Paris, France) for her donation of the villine-Cre (B6-Tg(Vil-cre)20Sy/Nci) mice. The authors greatly thank Valérie Gratio of the CRI cytometry facility. The authors are indebted Dr. Samira Benadda (INSERM U1149) for her assistance in confocal microscopy, and Olivier Thibaudeau (INSERM U1152) for help in histologic experiments.

This work was supported by French minister of higher education and research, INSERM and University Paris Diderot.

\section{Authors' contributions}

L.K. and E.C. conceived the study; L.K., P.J. and E.C. designed the experiments; L.K., E.C. and G.M. performed experiments; T.L., and F.W. performed histologic analyses; L.K., F.W., G.M., T.L, P.J.and E.C. analysed and interpreted data; L.K., and E.C. wrote the manuscript with comments from P.J., T.L. and F.W.

"Supplementary Information accompanies the paper on the Oncogene website (http:// www.nature.com/onc)"

\section{References}

1 Guinney J, Dienstmann R, Wang X, de Reyniès A, Schlicker A, Soneson C et al. The consensus molecular subtypes of colorectal cancer. Nature Medicine 2015; 21: $1350-1356$.

2 Kotelevets L, Chastre E, Desmaële D, Couvreur P. Nanotechnologies for the treatment of colon cancer: From old drugs to new hope. Int J Pharm 2016; 514: $24-40$. 
3 Jordan P, Brazåo R, Boavida MG, Gespach C, Chastre E. Cloning of a novel human Rac1b splice variant with increased expression in colorectal tumors. Oncogene 1999; 18: 6835-6839.

4 Goncalves V, Matos P, Jordan P. Antagonistic SR proteins regulate alternative splicing of tumor-related Rac1b downstream of the PI3-kinase and Wnt pathways. Hum Mol Genet 2009; 18: 3696-3707.

5 Wang F, Fu X, Chen P, Wu P, Fan X, Li N et al. SPSB1-mediated HnRNP A1 ubiquitylation regulates alternative splicing and cell migration in EGF signaling. Cell Res 2017; 27: 540-558.

6 Matos P, Collard JG, Jordan P. Tumor-related alternatively spliced Rac1b is not regulated by Rho-GDP dissociation inhibitors and exhibits selective downstream signaling. J Biol Chem 2003; 278: 50442-50448.

7 Matos P, Jordan P. Increased Rac1b expression sustains colorectal tumor cell survival. Mol Cancer Res 2008; 6: 1178-1184.

8 Matos P, Jordan P. Rac1, but not Rac1B, stimulates RelB-mediated gene transcription in colorectal cancer cells. J Biol Chem 2006; 281: 13724-13732.

9 Orlichenko L, Geyer R, Yanagisawa M, Khauv D, Radisky ES, Anastasiadis PZ et al. The 19-amino acid insertion in the tumor-associated splice isoform Rac1b confers specific binding to p120 catenin. J Biol Chem 2010; 285: 19153-19161.

10 Lee K, Chen QK, Lui C, Cichon MA, Radisky DC, Nelson CM. Matrix compliance regulates Rac1b localization, NADPH oxidase assembly, and epithelialmesenchymal transition. Mol Biol Cell 2012; 23: 4097-4108. 
11 Kang HT, Park JT, Choi K, Choi HJC, Jung CW, Kim GR et al. Chemical screening identifies ROCK as a target for recovering mitochondrial function in Hutchinson-Gilford progeria syndrome. Aging Cell 2017; 16: 541-550.

12 Matos P, Oliveira C, Velho S, Goncalves V, da Costa LT, Moyer MP et al. BRafV600E cooperates with alternative spliced Rac1b to sustain colorectal cancer cell survival. Gastroenterology 2008; 135: 899-906.

13 Alonso-Espinaco V, Cuatrecasas M, Alonso V, Escudero P, Marmol M, Horndler $\mathrm{C}$ et al. RAC1b overexpression correlates with poor prognosis in KRAS/BRAF WT metastatic colorectal cancer patients treated with first-line FOLFOX/XELOX chemotherapy. Eur J Cancer 2014; 50: 1973-1981.

14 Schnelzer A, Prechtel D, Knaus U, Dehne K, Gerhard M, Graeff H et al. Rac1 in human breast cancer: overexpression, mutation analysis, and characterization of a new isoform, Rac1b. Oncogene 2000; 19: 3013-3020.

15 Silva AL, Carmo F, Bugalho MJ. RAC1b overexpression in papillary thyroid carcinoma: a role to unravel. Eur J Endocrinol 2013; 168: 795-804.

16 Guo Y, Kenney SR, Muller CY, Adams S, Rutledge T, Romero E et al. Rketorolac targets cdc42 and rac1 and alters ovarian cancer cell behaviors critical for invasion and metastasis. Mol Cancer Ther 2015; 14: 2215-2227.

17 Ungefroren H, Sebens S, Giehl K, Helm O, Groth S, Fandrich F et al. Rac1b negatively regulates TGF- $\beta 1$-induced cell motility in pancreatic ductal epithelial cells by suppressing Smad signalling. Oncotarget 2014; 5: 277-290.

18 Mehner C, Miller E, Nassar A, Bamlet WR, Radisky ES, Radisky DC. Tumor cell 
expression of MMP3 as a prognostic factor for poor survival in pancreatic, pulmonary, and mammary carcinoma. Genes Cancer 2015; 6: 480-489.

19 Stallings-Mann ML, Waldmann J, Zhang Y, Miller E, Gauthier ML, Visscher DW et al. Matrix metalloproteinase induction of Rac1b, a key effector of lung cancer progression. Sci Transl Med 2012; 4: 142 ra95.

20 Zhou C, Licciulli S, Avila JL, Cho M, Troutman S, Jiang P et al. The Rac1 splice form Rac1b promotes K-ras-induced lung tumorigenesis. Oncogene 2013; 32: 903-909.

21 Kazanietz MG, Caloca M-J. The Rac GTPase in cancer: from old concepts to new paradigms. Cancer Res 2017; 77: 5545-5451.

22 Matos P, Jordan P. Expression of Rac1b stimulates NF-kappaB-mediated cell survival and G1/S progression. Exp Cell Res 2005; 305: 292-299.

23 Singh A, Karnoub AE, Palmby TR, Lengyel E, Sondek J, Der CJ. Rac1b, a tumor associated, constitutively active Rac1 splice variant, promotes cellular transformation. Oncogene 2004; 23: 9369-9380.

24 Radisky DC, Levy DD, Littlepage LE, Liu H, Nelson CM, Fata JE et al. Rac1b and reactive oxygen species mediate MMP-3-induced EMT and genomic instability. Nature 2005; 436: 123-127.

25 Matos P, Kotelevets L, Goncalves V, Henriques AFA, Henriques A, Zerbib P et al. Ibuprofen inhibits colitis-induced overexpression of tumor-related Rac1b. Neoplasia 2013; 15: 102-111.

26 Li G, Ying L, Wang H, Wei S-S, Chen J, Chen Y-H et al. Rac1b enhances cell 
survival through activation of the JNK2/C-JUN/Cyclin-D1 and AKT2/MCL1 pathways. Oncotarget 2016; 7: 17970-17985.

27 Sobhani I, Lehy T, Laurent-Puig P, Cadiot G, Ruszniewski P, Mignon M. Chronic endogenous hypergastrinemia in humans: evidence for a mitogenic effect on the colonic mucosa. Gastroenterology 1993; 105: 22-30.

28 Kotelevets L, Chastre E, Caron J, Mougin J, Bastian G, Pineau A et al. A Squalene-based nanomedicine for oral treatment of colon cancer. Cancer Res 2017; 77: 2964-2975.

29 Mahler JF, Stokes W, Mann PC, Takaoka M, Maronpot RR. Spontaneous lesions in aging FVB/N mice. Toxicologic Path 1996; 24: 710-716.

30 van de Wetering M, Sancho E, Verweij C, de Lau W, Oving I, Hurlstone A et al. The beta-catenin/TCF-4 complex imposes a crypt progenitor phenotype on colorectal cancer cells. Cell 2002; 111: 241-250.

31 Esufali S, Charames GS, Pethe VV, Buongiorno P, Bapat B. Activation of tumorspecific splice variant Rac1b by dishevelled promotes canonical Wnt signaling and decreased adhesion of colorectal cancer cells. Cancer Res 2007; 67: 24692479.

32 Pethe VV, Charames GS, Bapat B. Rac1b recruits Dishevelled and $\beta$-catenin to Wnt target gene promoters independent of Wnt3A stimulation. Int J Oncol 2011; 39: 805-810.

33 Farin HF, Jordens I, Mosa MH, Basak O, Korving J, Tauriello DVF et al. Visualization of a short-range Wnt gradient in the intestinal stem-cell niche. 
Nature 2016; 530: 340-343.

34 Stappenbeck TS, Gordon JI. Rac1 mutations produce aberrant epithelial differentiation in the developing and adult mouse small intestine. Development 2000; 127: 2629-2642.

35 Andreu P, Peignon G, Slomianny C, Taketo MM, Colnot S, Robine S et al. A genetic study of the role of the Wnt/beta-catenin signalling in Paneth cell differentiation. Dev Biol 2008; 324: 288-296.

36 Sato $\mathrm{T}$, van Es JH, Snippert HJ, Stange DE, Vries RG, van den Born M et al. Paneth cells constitute the niche for Lgr5 stem cells in intestinal crypts. Nature 2011; 469: 415-418.

37 Rodríguez-Colman MJ, Schewe M, Meerlo M, Stigter E, Gerrits J, Pras-Raves M et al. Interplay between metabolic identities in the intestinal crypt supports stem cell function. Nature 2017; 543: 424-427.

38 Myant KB, Cammareri P, McGhee EJ, Ridgway RA, Huels DJ, Cordero JB et al. ROS production and NF-KB activation triggered by RAC1 facilitate WNT-driven intestinal stem cell proliferation and colorectal cancer initiation. Cell Stem Cell 2013; 12: 761-773.

39 Kato M, Marumo M, Nakayama J, Matsumoto M, Yabe-Nishimura C, Kamata T. The ROS-generating oxidase Nox1 is required for epithelial restitution following colitis. Exp Anim 2016; 65: 197-205.

40 Curtis KM, Gomez LA, Schiller PC. Rac1b regulates NT3-stimulated Mek-Erk signaling, directing marrow-isolated adult multilineage inducible (MIAMI) cells 
toward an early neuronal phenotype. Mol Cell Neurosci 2012; 49: 138-148.

41 Mori Y, Yagi S, Sakurai A, Matsuda M, Kiyokawa E. Insufficient ability of Rac1b to perturb cystogenesis. Small GTPases 2013; 4: 9-15.

42 Espinha G, Osaki JH, Magalhaes YT, Forti FL. Rac1 GTPase-deficient HeLa cells present reduced DNA repair, proliferation, and survival under UV or gamma irradiation. Mol Cell Biochem 2015; 404: 281-297.

43 Lessel W, Silver A, Jechorek D, Guenther T, Roehl F-W, Kalinski T et al. Inactivation of JNK2 as carcinogenic factor in colitis-associated and sporadic colorectal carcinogenesis. Carcinogenesis 2017; 38: 559-569.

44 Cole AM, Ridgway RA, Derkits SE, Parry L, Barker N, Clevers H et al. p21 loss blocks senescence following Apc loss and provokes tumourigenesis in the renal but not the intestinal epithelium. EMBO Mol Med 2010; 2: 472-486.

\section{Figure Legends}

\section{Figure 1. Characterization of villin-Cre Rac1b mice.}

A) Rac1b mRNA levels in the small intestine (duodenum, jejunum, ileum) and in the colon (proximal and distal) were investigated by RT-qPCR. Upper panel, the values were normalized using the S14 housekeeping gene, and standardized with the value measured in the duodenum from wild-type animals, used as reference. Results are expressed as $\log _{2}$ scale, and are the mean of RT-qPCR performed on RNA extracted from wild-type animals (6 small intestines, 14 colons); villin-Cre LSL-Rac1bflox/- mice 
(4 small intestines, 11 colons), and villin-Cre LSL-Rac1b floxflox mice (4 small intestines, 4 colons).

Middle panel, the relative accumulation of Rac1b vs. total Rac1 was determined

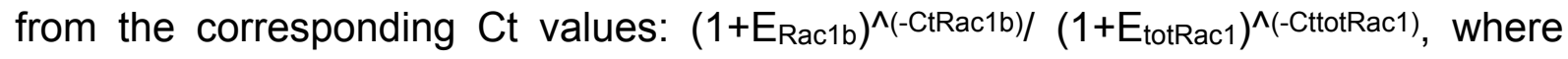
$E_{\text {Rac1b }}$ and $E_{\text {totRac1 }}$ correspond to Rac1b and total Rac1 qPCR efficiencies (1.03 and 0.96, respectively).

Lower panel, western blot analysis of Rac1b and Rac1 in intestinal mucosa of wildtype animals, villin-Cre LSL-Rac1 $b^{\text {floxl- }}$ and villin-Cre LSL-Rac1 $b^{\text {floxfllox }}$ mice (4 animals for each group). The relative accumulation of Rac1b normalized with total Rac1 was determined using ImageJ (histogram).

B) Histological analysis of the small intestine and the colon of villin-Cre LSLRac1bfloxflox mice. Small intestine and colon from wild-type and villin-Cre LSLRac 1 bfloxflox mice aged 18 months were swiss rolled, fixed, and the corresponding section were subjected to HPS staining (left panels). No histological lesion was identified along the whole intestine. Right panels: enlargement of the ileal and distal colon showing that the mucosal architecture was not affected by Rac1b overexpression. Scale bars: $100 \mu \mathrm{m}$.

\section{C) Rac1b enhanced ROS production by colonic epithelial cells.}

Dihydroethidium staining was increased in villin-Cre LSL-Rac1bfloxfllox (lower panel) mice intestine compared with wild-type animals (upper panel).

\section{D) Rac1b promoted paneth cells differentiation in ileal crypts.}

Paneth cells (arrows) are located at the base of the crypts of Lieberkühn, and are characterized by large eosinophilic refractile secretory granules that occupy most of their cytoplasm (Mm: muscularis mucosae). The number of Paneth cells in 
histological ileum sections stained with HPS was quantitated. Scale bar: $100 \mu \mathrm{m}$. Accumulation of cryptdin transcripts was analysed by RT-qPCR.

E) Rac1b enhanced nuclear $\beta$-catenin accumulation in intestinal crypts. Immunohistochemistry of $\beta$-catenin revealed an increased in labeled nuclei in the bottom of ileal crypts of Rac1b transgenic mice. Scale bar: 100um.

Figure 2. Rac1b overexpression stimulated proliferation and migration of intestinal epithelial cells but did not enhance crypt cellularity, crypt depth or villus height.

(A, B) The number of proliferating cells in colonic crypts was assessed by immunostaining of KI67 or BrdU injected 3h prior sacrifice. The percentage of KI67 and $\mathrm{BrdU}$ immunoreactive cells per crypt was quantified in at least 15 well-oriented hemicrypts in the distal colon from wild-type and villin-Cre LSL-Rac1bfloxflox mice. Representative immunostaining of KI67 and BrdU (right panels). The relative position and the unicity of the proliferative compartment were preserved. Scale bar: $100 \mu \mathrm{m}$. Statistical differences were determined using two-tailed unpaired t-test.

C) Morphometric analysis revealed that the colonic crypt depth and the number of epithelial cells per hemicrypt were similar in wild-type and villin-Cre LSL-Rac1bfloxflox animals. Statistical differences were analyzed using two-tailed unpaired t-test. D) Cell migration along the crypt-villus axis of the small intestine was quantified by immunostaining of BrdU injected in wild-type and villin-Cre LSL-Rac1bfloxflox mice 20h prior sacrifice. The utmost position of BrdU positive cells (black arrows) determined in at least 20 full length villi for each animal was significantly increased in transgenic mice as compared with control. Nevertheless, villus height was not affected. 
Statistical differences were determined using two-tailed unpaired t-test. Scale bar: $100 \mu \mathrm{m}$.

Figure 3. Clinical and histological features of villin-Cre LSL-Rac1 $1 b^{\text {flox/flox }}$ and wild-type mice during the acute and the recovery phases of DSS-induced colitis.

A) Percentage of body weight loss of villin-Cre LSL-Rac1 bflox/- (upper panel) or villinCre LSL-Rac1 $\mathrm{b}^{\text {flox/flox }}$ transgenic mice (lower panel) vs. wild-type mice. Weight loss during DSS administration is a surrogate marker for colitis severity. Values are means \pm SEM of one representative experiment out of 3 .

B) The disease activity index (DAI). DAI was calculated daily for each mouse as a 0-4 scoring system taking into account weight loss, stool consistency, blood in stool or rectal bleeding. Note that the DAI curves for villin-Cre LSL-Rac1bflox/flox and wildtype mice were superimposable.

C) Colon length was assessed at necropsy on day 7 following DSS exposure. As expected, wild-type $(n=30)$, and villin-Cre LSL-Rac1 $b^{\text {flox/- }}(n=14)$ and villin-Cre LSLRac1bfloxflox $(n=7)$ transgenic mice have shorter colons after DSS-induced colitis. These changes were similar in the 3 groups of animals. Differences were evaluated by ANOVA followed by Tukey's post hoc test.

D) Colonic mucosal lesions and repair after DSS-induced colitis. The extent of mucosal lesion and tissue repair were investigated on histological sections from wildtype $(n=6)$ and villin-Cre LSL-Rac1bflox/flox $(n=7)$ DSS-treated mice. Statistical differences were analyzed using two-tailed unpaired t-test. 
E) Kaplan-Meier survival curves. Differences between survival of villin-Cre LSLRac1bfloxflox $(n=46)$ and wild-type $(n=51)$ mice after DSS treatment were calculated using the log-rank test.

F) Percentage of body weight loss of Rac1b transgenic mice $(n=9)$ and wild-type $(n=7)$ after 5 days of treatment with $3 \%$ DSS followed by 7 days with sterilized drinking water. Died or euthanized mice in the course of the experiment were not included in the final analysis. Values are means of one representative experiment \pm SEM out of 3. Statistical differences were determined using two-tailed unpaired t-test. ${ }^{*} \mathrm{p}<0.05$

G) Tissue repair was investigated by histology and expressed as the percentage of regenerative issue vs. initial lesion length. Statistical differences were determined using two-tailed unpaired t-test.

H) Histology of colonic mucosa of control (upper panel) and villin-Cre LSL-Rac1bflox/ flox (lower panel) mice 7 days after DSS treatment. Right panels: enlargement. Arrows: regenerating epithelium. Scale bars: $100 \mu \mathrm{m}$.

Figure 4. Rac1b ectopic expression alleviated carcinogen (AOM)/ accute inflammation (DSS) -associated colorectal cancer.

A) Schematic of AOM and DSS administration. AOM $(7.5 \mathrm{mg} / \mathrm{kg})$ was injected on day 0 and on day 7 . At the beginning of the third week, $2 \%$ DSS solution was administered to mice in their drinking water, followed by administration of autoclaved tap water during five weeks prior to sacrifice. Lower panel: macroscopic view of colon from wild-type and villin-Cre LSL-Rac1 $1 b^{\text {floxfflox }}$ mice. Note the majority of tumors are located in the distal colon. B) Histological analysis of colon tumors from wild-type and villin-Cre LSL-Rac1 bfloxflox mice (HPS staining). Scale bar: $100 \mu \mathrm{m}$. 
C) Left panel: Representative distribution of the average number of colon tumors in AOM-DSS treated wild-type and villin-Cre LSL-Rac1 $b^{\text {floxflox }}$ mice. Results present the compilation of 2 experiments performed with 8 control and 11 villin-Cre LSL-Rac1 1 flox/ flox mice for the $1^{\text {st }}$ experiment, and 8 wild-type and 10 villin-Cre LSL-Rac1bfloxflox mice for the $2^{\text {nd }}$. Right panel: Total colon tumor area in the AOM-DSS treated wildtype and villin-Cre LSL-Rac1 $b^{\text {floxfllox }}$ mice. Statistical differences were determined using two-tailed unpaired t-test.

D) Correlation plot for weight loss during the acute phase of DSS treatment vs. number of colon tumors per mice (left panel) or tumor area at necropsy (right panel). Pearson's correlations Matrix $p<0.05$ for control and villin-Cre Rac $1 b^{\text {floxfllox }}$ groups.

Figure 5. Rac1b cooperated with Apc inactivation to promote intestinal carcinogenesis.

A) Rac1b and CXCL2/MIP2 $\alpha$ expression in intestinal tumors from Apc $\mathrm{Ain} /+^{\mathrm{m}}$ mice. RT-PCR analyses were performed in small intestinal and colonic tumor samples paired with adjacent control mucosa isolated from APCMin/+ mice. The relative accumulation of CXCL2/MIP2 $\alpha$ transcripts, Rac1b and cytokeratin-8 (K8) -a marker of intestinal epithelial cells- relative to paired control mucosa are expressed as $\log _{2}$ scale.

B) Numbers and size distribution of adenomas in the small intestine from $\mathrm{Apc}^{\mathrm{Min} /+}$ and villin-Cre LSL-Rac1bflox/- Apc $\mathrm{Min} /+^{+}$mice.

Upper panel: Relative distribution of tumors expressed as the percentage of tumors in each segment vs. total number of tumors. Lower panel: Distribution profile of adenomas in the small intestine as a function of their size. Polyps were classified into nine classes. The size of most polyps ranged between $500 \mu \mathrm{m}$ and $3 \mathrm{~mm}$. 
C) The number of tumors in the small intestine (upper panel) and colon (lower panel). was significantly increased in villin-Cre LSL-Rac1 $b^{\text {floxl- }} \mathrm{Apc}$ Min/+ mice as compared with $\mathrm{Apc} \mathrm{Min} /+^{\mathrm{a}}$ animals.

Figure 6. Cooperative effects of Rac1b ectopic expression and II10 knockout in colon carcinogenesis.

A) Left panels: number of mice developing tumor in cecum and in proximal colon. villin-Cre LSL-Rac1 $b^{\text {floxfflox }}(n=32)$, II10-/- mice $(n=40)$ and villin-Cre LSL-Rac1 bfloxflox II10- mice $(n=9)$ were sacrificed at 16 weeks, the colon tumors were quantified. Differences were evaluated by ANOVA followed by Tukey's post hoc test.

Right panels: Representative aspect of mucin secreting tumors in proximal colon of villin-Cre LSL-Rac1bfloxfllox II10-/- mouse. Scale bar: $1 \mathrm{~mm}$.

B) Accumulation of the transcripts encoding proinflammatory cytokine in the distal and proximal colon of wild-type, villin-Cre LSL-Rac1 $b^{\text {flox/flox, }} \| 110^{-/-}$and villin-Cre LSL-Rac1 $b^{\text {flox/flox }} \| 110^{-/-}$mice. Differences were evaluated by ANOVA followed by Tukey's post hoc test.

C) Transepithelial conductance of the proximal colon of wild-type, villin-Cre LSL-Rac1 $b^{\text {floxflox }}$ evaluated using Ussing chambers ( $\mathrm{n}=6 \mathrm{mice} /$ group).

D) Overall mice survival.

Differences between survival of villin-Cre LSL-Rac1 $b^{\text {floxflox }}(n=40), \| 10^{-/-}(n=45)$ and villin-Cre LSL-Rac1 $b^{\text {floxfflox }} \| 10^{-\digamma}(n=22)$ mice were calculated using the log-rank test.

Figure 7. Proposed mechanism accounting for the dual role of Rac1b in tissue repair and in carcinogenesis.

Under physiological conditions or after acute inflammation, Rac1b drives the differentiation of Paneth cells, stimulates Wnt pathway, DNA damage response and 
promotes cell proliferation and cell migration. These processes might favor tissue repair after intestinal lesions. Under a pathological context, Rac1b can cooperate with oncogenic pathways, e.g. Wnt signaling, or can strenghten chronic colitis as a result of impaired intestinal barrier function leading to carcinogenesis. 
A
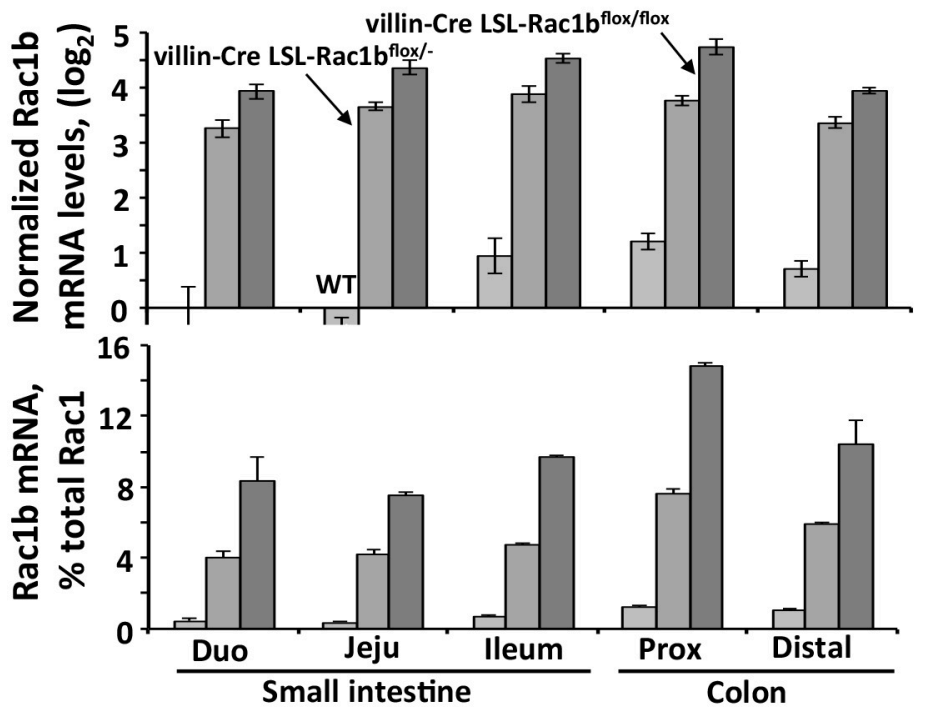

\section{B Small intestine}
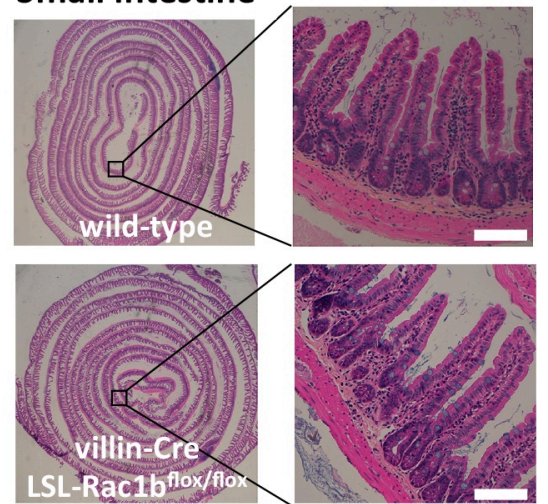

Colon
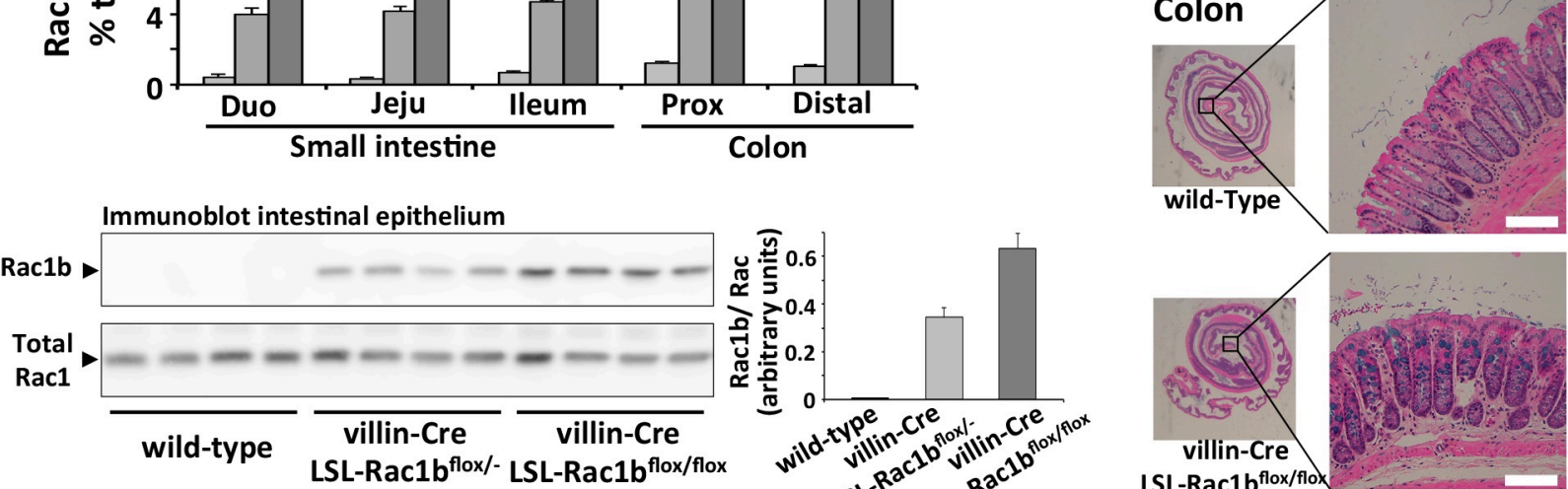

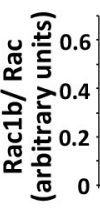

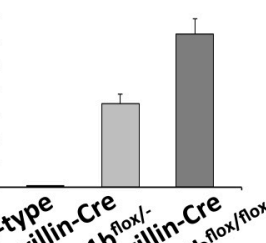

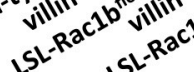

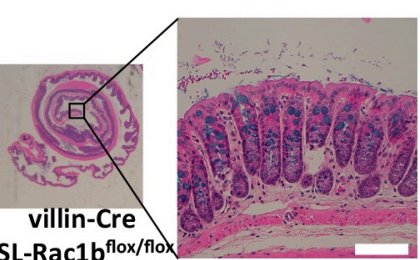

C
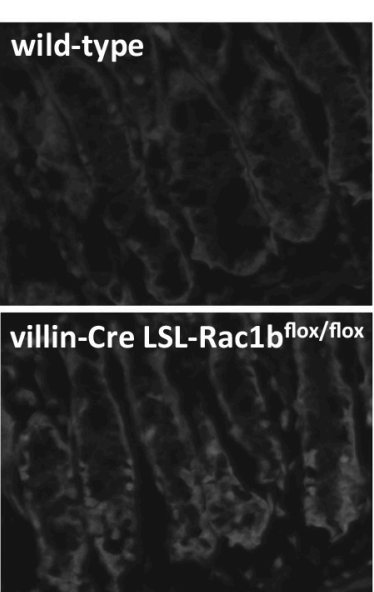

Dihydroethidium labeling
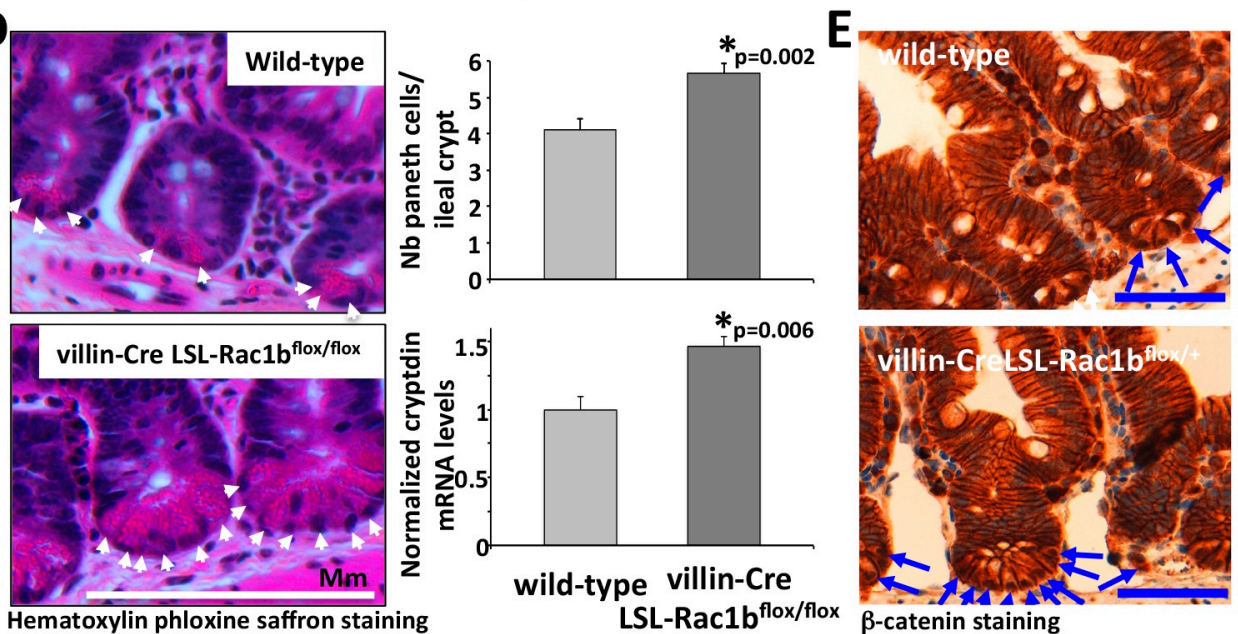

Hematoxylin phloxine saffron staining

$\beta$-catenin staining

Figure 1 

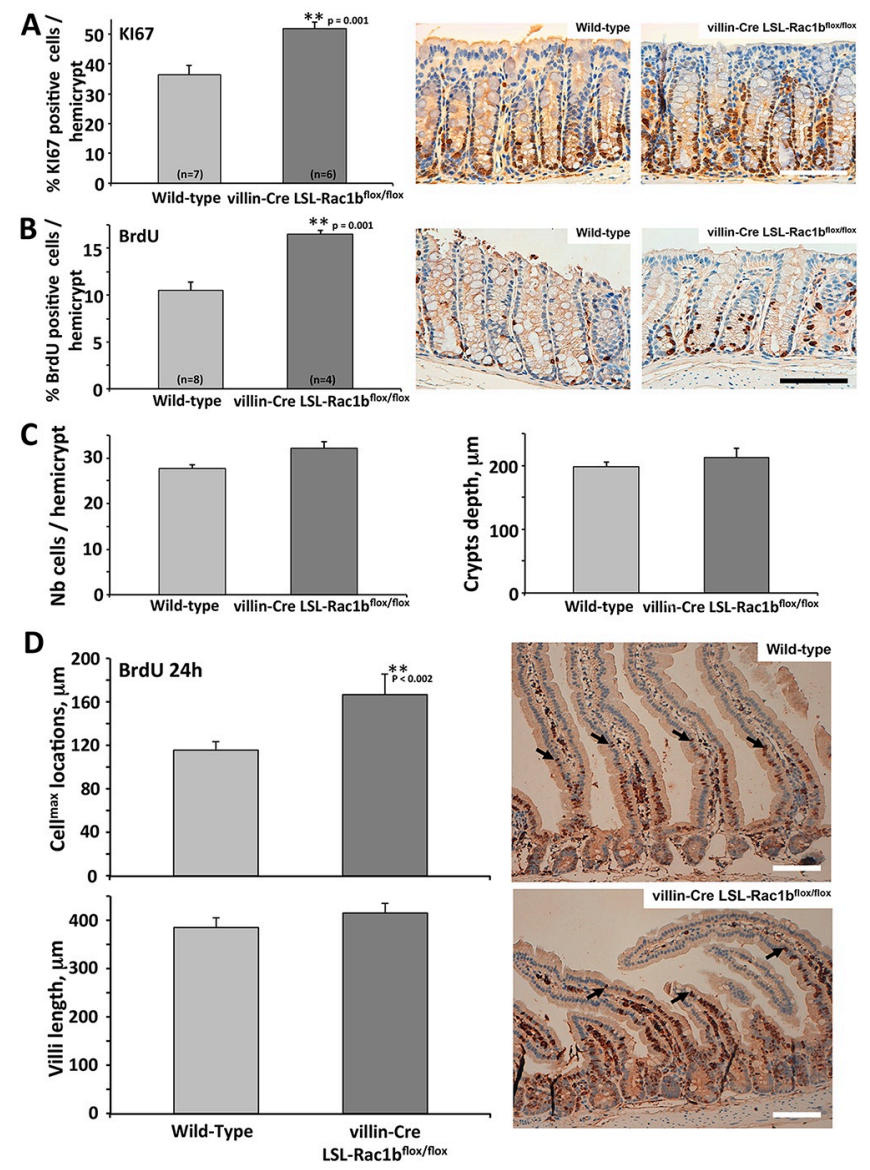

Figure 2 
Acute phase
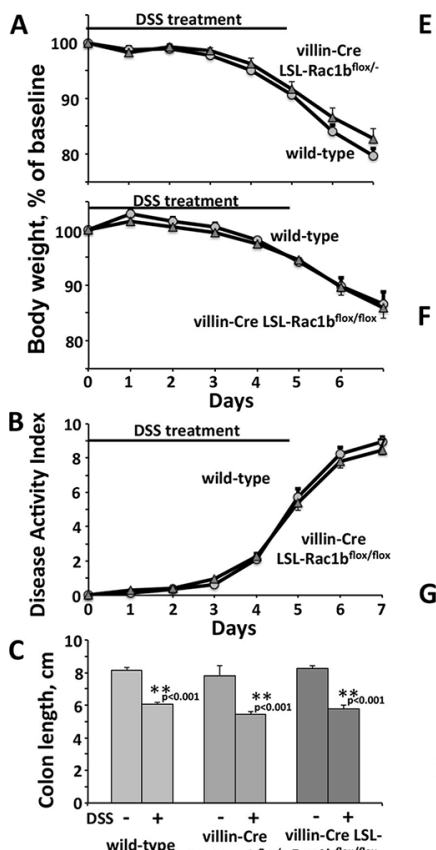

G
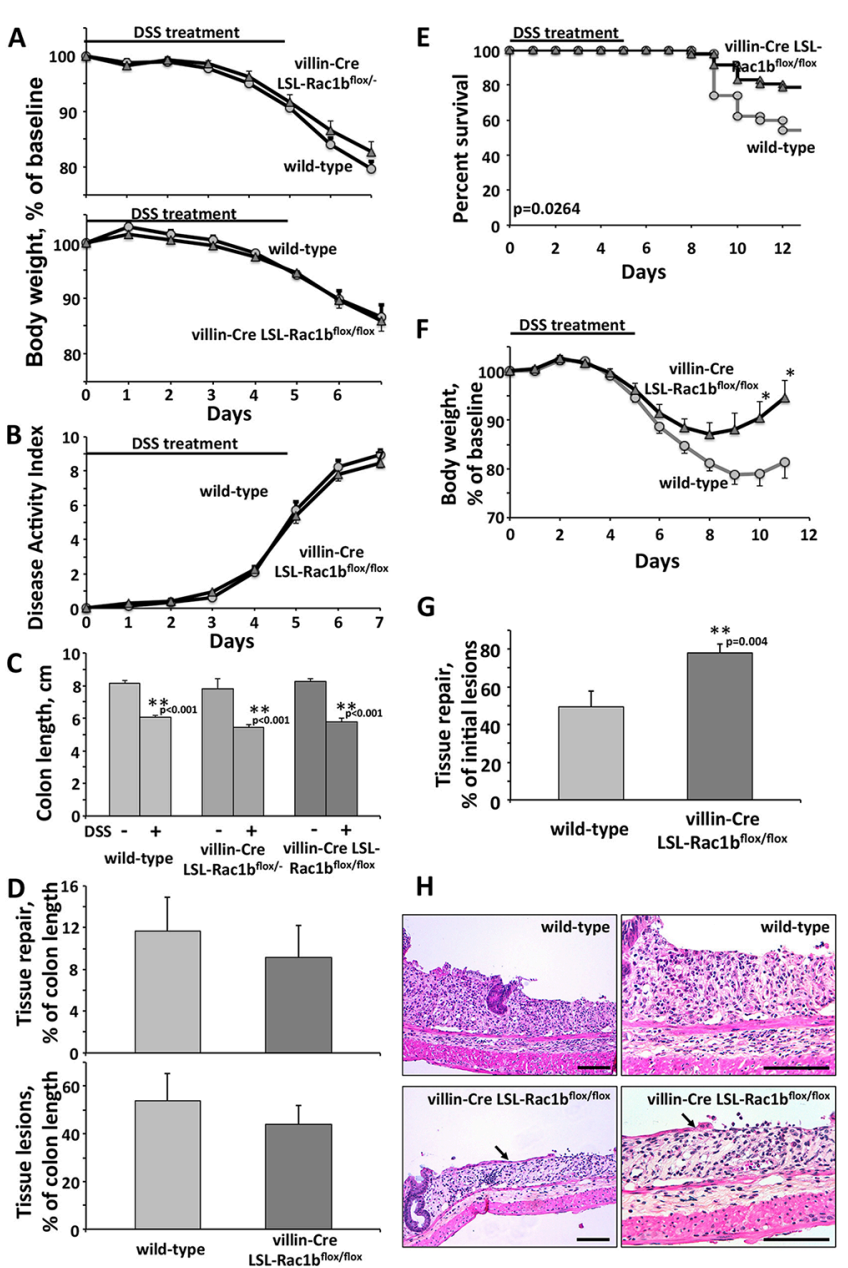

Figure 3 

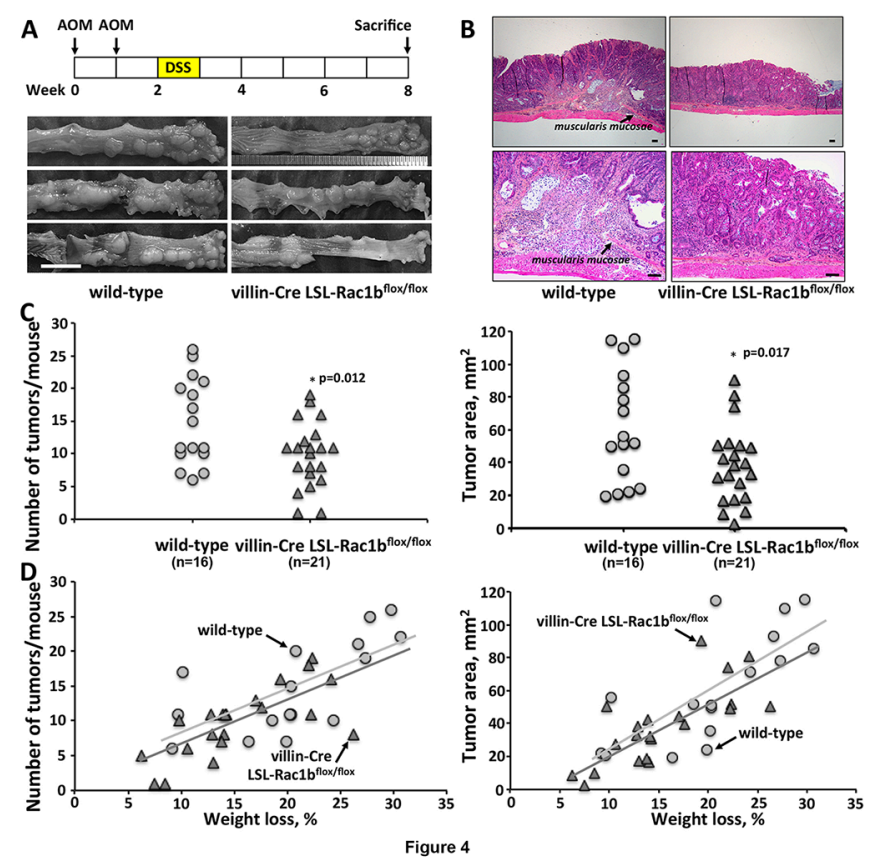

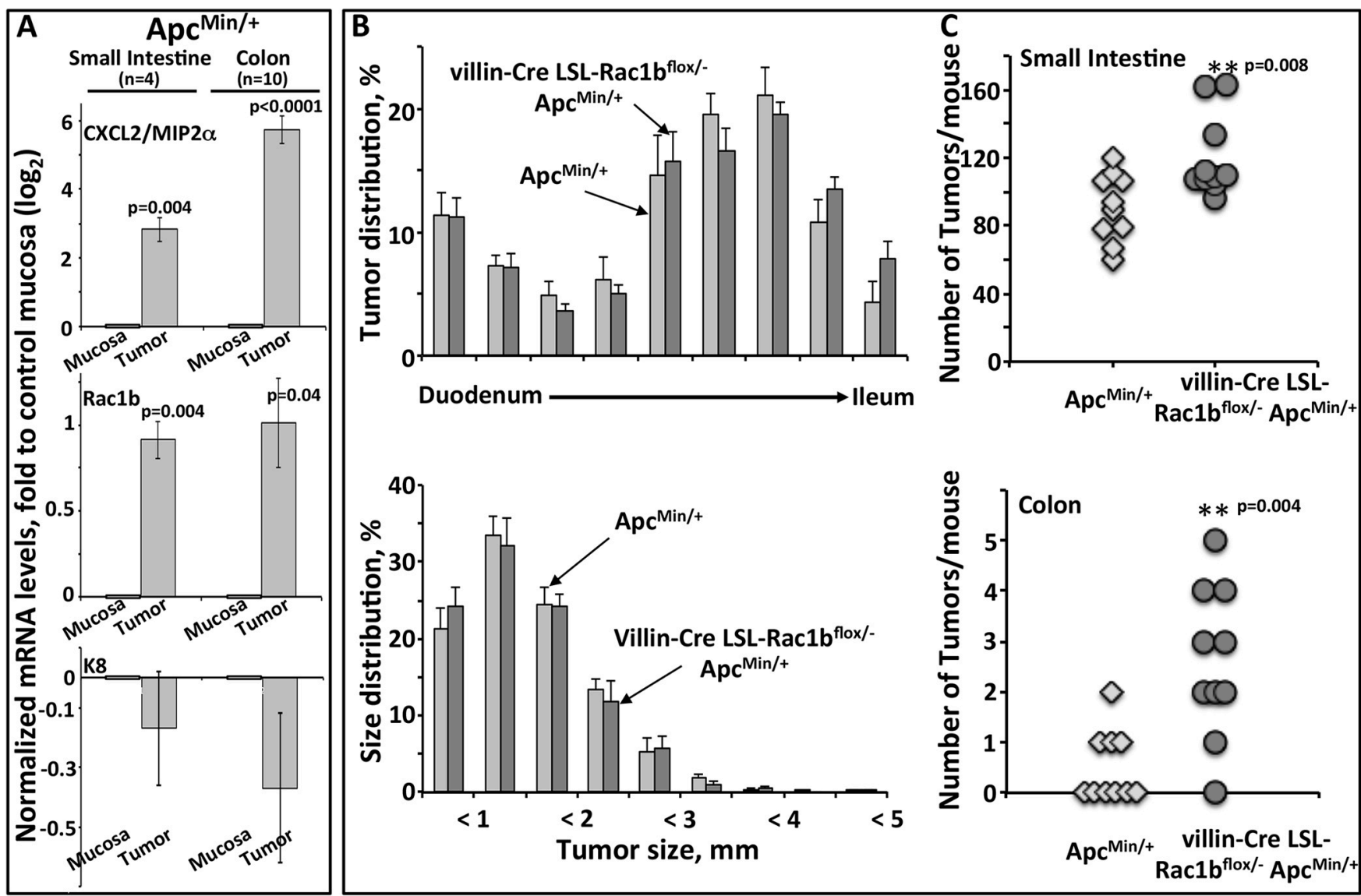

Figure 5 

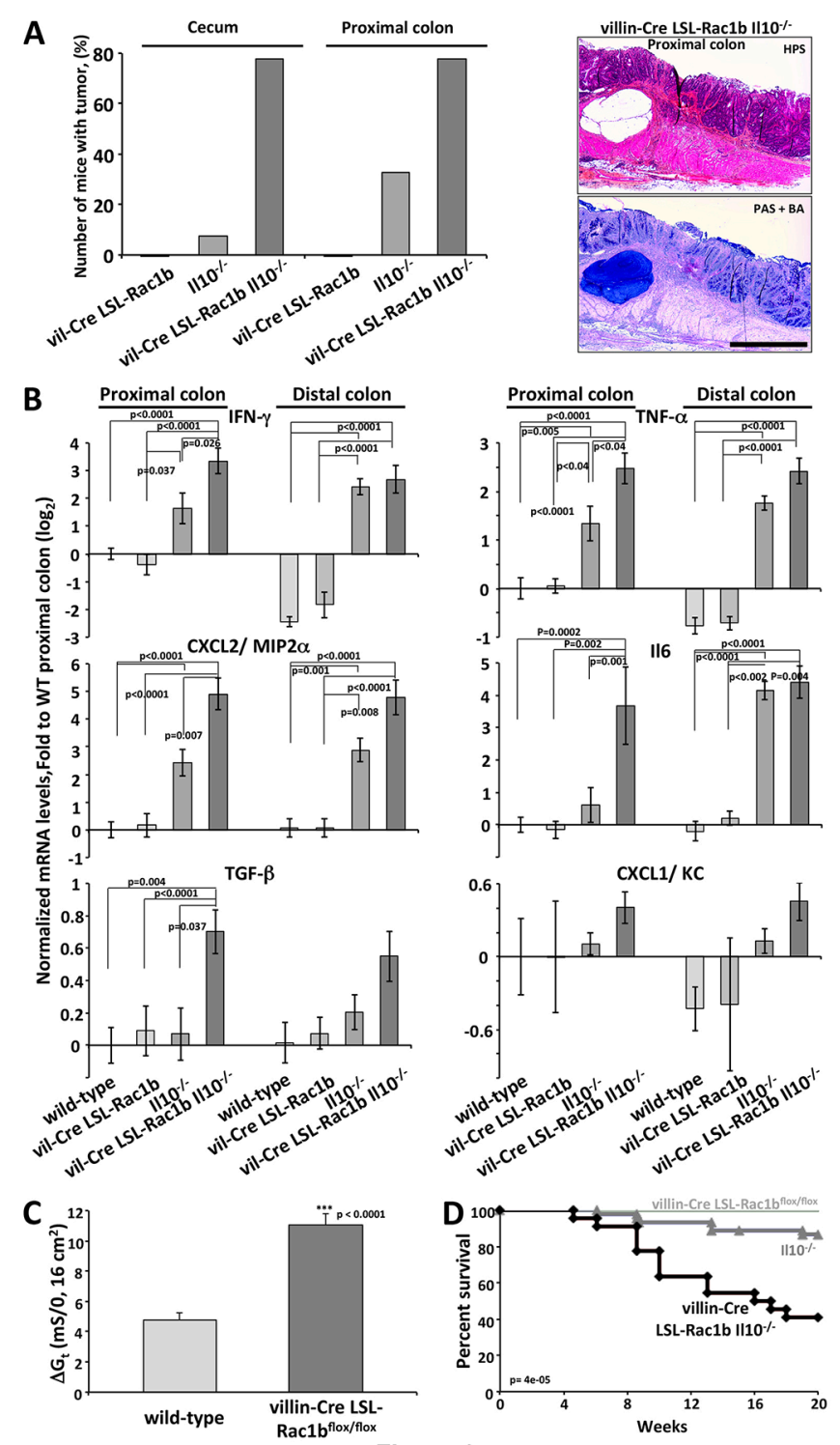

Figure 6 


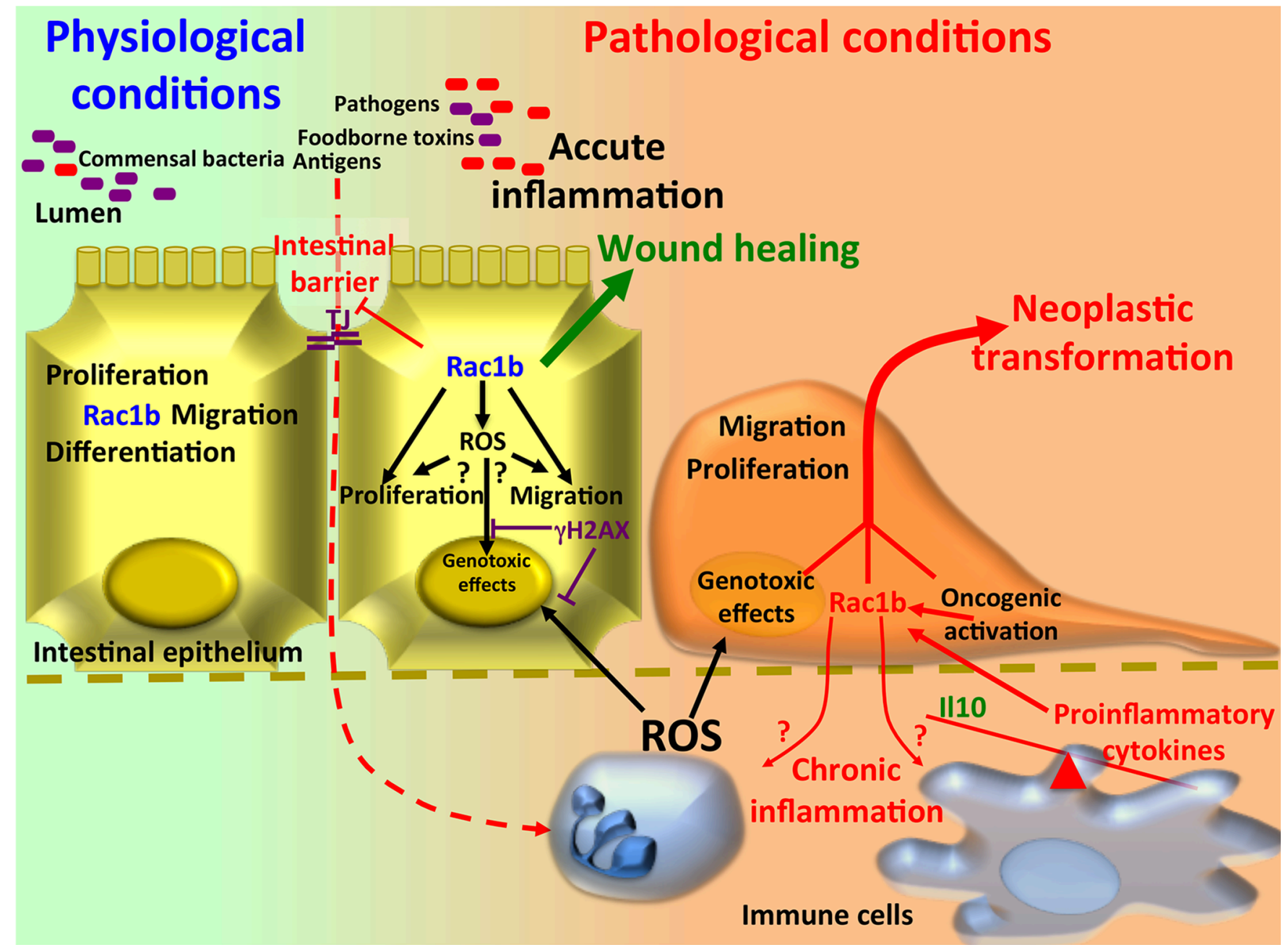

Figure 7 


\section{Supplementary Methods}

\section{Animals}

The Rosa26-LSL-Rac1b transgenic mice were generated by Zhou et al and donated to the Jacksons Laboratories by J. Kissil. The Rosa26-LSL-Rac1b allele contains a loxP-flanked neo-STOP cassette (-LSL-) upstream of human Rac1b cDNA inserted into the Gt(ROSA)26Sor locus¹. The C57BI6J-ApcMin/+ mice bear a heterozygous nonsense mutation at the region corresponding to codon 850 of the Apc gene. These mice develop numerous adenomas/carcinomas in the small intestine and in the colon and have a reduced average lifespan of about 150 days. The B6.129P2- $1110^{\operatorname{tm} 1 \mathrm{Cgn}}$ mice were delivered to the Jacksons Laboratories by Dr. Sandy Morse, National Institutes of Health. The invalidation of II10 gene results from the replacement of a 500 bp genomic fragment containing codons 5-55 of II10 with a linker containing a termination codon followed by a neomycin cassette, a termination codon was also introduced into exon 3 . The villin-Cre ${ }^{+/-}$transgenic mice were generated and kindly provided by $\mathrm{S}$. Robine (Institut Curie, France). These mice express the Cre recombinase in villus and crypt epithelial cells of the small and large intestines ${ }^{2}$.

Mouse genotyping was performed by PCR amplification of genomic DNA isolated from tail biopsies by solid-phase extraction, using the NucleoSpin Tissue kit (Macherey Nagel). For Rosa LSL-Rac1b, we used the following set of primers for multiplex PCR: common sense 5'- TCAGTAAGGGAGCTGCAGTG -3'; wild-type antisense 5'- CAGCCTCGATTTGTGGTGTA -3'; and mutant antisense 5'GCGAAGAGTTTGTCCTCAACC -3', generating amplicons of 300 bp and 759 bp for the mutant and wild-type allele, respectively. For ApcMin/+ mice, we used sense 5'GCCATCCCTTCACGTTAG -3' (wild-type) and 5'-TTCTGAGAAAGACAGAAGTTA -3' -final adenosine residue corresponds to the $\mathrm{T}$ to $\mathrm{A}$ transversion at nucleotide 2549 in 
C57BL/6J-ApcMin/+ mice; and antisense 5'- TTCCACTTTGGCATAAGGC -3' oligonucleotides. The expected size of the PCR products was $600 \mathrm{bp}$ for wild-type animals. For the C57BL/6J-ApcMin/+ mice, two additional bands of $340 \mathrm{bp}$ and 1000 bp were obtained, corresponding to the amplification of the mutant allele and the heteroduplex (wild-type/mutant allele), respectively. For C57BL/6J-II10-/- mice, we used the common sense 5'- CTTGCACTACCAAAGCCACA -3'; the wild-type antisense 5'- GTTATTGTCTTCCCGGCTGT -3'; and the mutant antisens 5'CCACACGCGTCACCTTAATA -3'. The expected size of the PCR products was 137 bp for wild-type animals, $312 \mathrm{bp}$ for $\| 10^{-/-}$mice, and $137 \mathrm{bp}$ and $312 \mathrm{bp}$ for heterozygous animals. For the villin-Cre transgenic mice, we used the sense 5'CAAGCCTGGCTCGACGGCC -3' and antisense 5'- CGCGAACATCTTCAGGTTCT -3 ' primers, providing an amplicon of approximately 300bp.

The villin-Cre ${ }^{+/}$LSL-Rac1bflox/flox mice were generated by crossing Rosa26-LSLRac1b animals with villin-Cre ${ }^{+/-}$mice followed by the backcross of the villin-Creflox/LSL-Rac1b flox/- progeny with Rosa26-LSL-Rac1b. The Rac1bflox/flox (villin-Cre-/-) mice were considered as control group. In all experiments littermate controls were used assuring comparison of mice on the same genetic background. The villin-Cre ${ }^{+/-} \mathrm{LSL}-$ Rac1b flox/- ApcMin/+ double mutant mice were produced by crossing villin-Cre ${ }^{+/-}$LSLRac1b flox/flox mice and $\mathrm{Apc}^{\mathrm{Min} /+}$ animals.

To minimize cage/ microbiote effects, the villin-Cre ${ }^{+/-}$LSL-Rac1 $1 b^{\text {flox/flox }}$ and control littermates were systematically gathered and co-housed. All mice were maintained under standard pathogen-free conditions in ventilated cages with sterile food and water ad libitum.

Wild-type and Rac1b transgenic mice with the similar weight were randomized to experimental groups. During the experimental treatments, wild-type and Rac1b 
transgenic mice were maintained cohoused as control or treated groups, and the pathophysiological parameters were blindly monitored.

The sample size estimate was chosen based on previous studies demonstrating that $\mathrm{n}=5$ was adequately powered to detect a significant change between groups.

For the survival study of DSS -treated mice, 46 villin-Cre LSL-Rac1 $1 b^{\text {flox/flox }}$ and 51 wild-type mice were used. For AOM/DSS -induced colon carcinogenesis, 8 wild-type and 11 villin-Cre LSL-Rac1 $b^{\text {flox/flox }}$ mice were used for the $1^{\text {st }}$ experiment, and 8 wildtype and 10 Rac1b transgenic mice for the 2 nd. For cooperation of Rac1b ectopic expression with Apc inactivation, 10 mice in each genotype were enrolled. For the survival study cooperative effects of Rac1b ectopic expression with II10 knockout, 40 villin-Cre LSL-Rac1 $\mathrm{b}_{\text {flox/flox, }} 45$ II10-/- and 22 villin-Cre LSL-Rac1 $\mathrm{b}_{\text {flox/flox }} \| 10^{-/-}$mice were enrolled. For the histological and immunohistological studies, at least 5 mice in each genotype were analyzed. See also Legends to (Supplementary/) Figures for further informations.

For survival analysis, survival refers to mice that died unexpectedly or were euthanized once they exceeded approved experimental end points for animal health. For 5-bromo-2'-deoxyuridine (BrdU) immunohistochemistry, mice were injected intraperitoneally with $2 \mathrm{mg}$ of bromodeoxyuridine (BrdU; Sigma-aldrich, St Quentin Fallavier, France) $3 \mathrm{~h}$ or $20 \mathrm{~h}$ prior to euthanasia, to determine the proliferative index and the intestinal epithelial cell migration rates, respectively.

\section{Disease activity index}

During the DSS treatment and the recovery phase, animal were observed daily for weight, water/food consumption, morbidity, stool consistency, piloerection, and the presence of gross blood in feces and at the anus. 
Disease activity index (DAI) was calculated as follows:

i) Weight loss $(0$ point $=$ none, 1 point $=1-5 \%$ weight loss, 2 points $=5-10 \%$ weight loss, 3 points $=10-15 \%$ weight loss, and 4 points $=$ more than $15 \%$ weight loss),

ii) Stool consistency/diarrhea $(0$ points $=$ normal, 2 points $=$ loose stools, 4 points $=$ watery diarrhea),

iii) Bleeding ( 0 points $=$ no bleeding, 2 = slight bleeding, 4 points $=$ gross bleeding $)$.

The DAI was calculated as the total of these scores: the sum of weight loss, diarrhea, and bleeding, resulting in the total DAI score ranging from 0 (unaffected) to 12 (severe colitis).

\section{Isolation and fractionation of colonic crypts}

Isolation and fractionation of colonic epithelial cells was performed as previously described $^{3}$. The colons were dissected, flushed, everted, ligated at one edge with surgical thread and filled to distension with PBS before closing the remaining open end. Right colons were washed with shaking in PBS buffer containing $1 \mathrm{mM}$ dithiothreitol (DTT) and then transferred into EDTA buffer (1 mM EDTA in PBS, 0.5 mM DTT) and placed on a shaking platform at room temperature. Two fractions of colonic crypts were collected after four consecutive incubation steps in EDTA buffer (20 minutes each): the 2 first were pooled and designed : colonic crypts top fraction and the two last : crypts bottom fraction.

\section{Transepithelial electrical conductance measurement}

For transepithelial electrical conductance experiments, animals were fasted for $16 \mathrm{~h}$ with full access to drinking water. Colons were collected immediately after the mice were killed, opened along the mesenteric border, and the proximal portion was 
mounted in a $0.16 \mathrm{~cm}^{2}$ Ussing chamber. Throughout the experiment, tissues were maintained in circulating oxygenated Ringer solution at $37^{\circ} \mathrm{C}(\mathrm{pH} 7.4)$. Electrical parameters were monitored $15 \mathrm{~min}$ after equilibrium. The spontaneous transmural electrical potential difference (PD) reflecting the asymmetry of electrical charges between the luminal and serosal mucosa was measured via $3 \mathrm{M} \mathrm{KCl}$ solution in $4 \%$ $(w / v)$ agar bridges. These bridges were placed on both sides of the tissue and connected to calomel half-cells, linked to a high-impedance voltmeter. PD was shortcircuited and maintained at $0 \mathrm{mV}$ throughout the experiment by a short-circuit current (Isc) via two stainless steel 316 L working electrodes directly placed in each reservoir as described by Mathieu et al.4,5, in relation with an automatic voltage-clamp system (JFD-1V, Laboratoires TBC \& Biomécatronics SAS, Ruitz, France).

Delivered Isc, corrected for fluid resistance, was recorded continuously on a computer with Biodaqsoft software (Laboratoires TBC \& Biomécatronics SAS, Ruitz, France). The Isc (in $\mathrm{mA} / \mathrm{cm} 2$ ) represents the sum of the net ion fluxes transported across the epithelium in the absence of an electrochemical gradient (mainly $\mathrm{Na}^{+}, \mathrm{Cl}^{-}$ and $\left.\mathrm{HCO}^{-}\right)$.

The transepithelial electrical conductance Gt was established from the measurements of the short-circuit current (Isc) and the potential difference (PD) taken at time intervals $(0,30,60$ and $90 \mathrm{~min})$ and calculated according to the following equation : $\mathrm{Gt}=$ Isc/PD. Gt reverse of resistance a permeability parameter was expressed in $\mathrm{mS} / \mathrm{cm}^{2}$.

\section{Immunoblotting analysis}

Intestinal epithelium was homogenized in $10 \mathrm{mmol} / \mathrm{L}$ Tris- $\mathrm{HCl}, 150 \mathrm{mmol} / \mathrm{L} \mathrm{NaCl}, 1 \%$ Triton X-100, and a cocktail of protease inhibitors (P8340, Sigma Aldrich, St. Quentin 
Fallavier, France). After protein normalization and denaturation in Laemmli buffer, cell extracts were separated on polyacrylamide gels, blotted onto Protran nitrocellulose membranes (Merck-Millipore, Molsheim, France), and probed with a mouse mAb directed against Rac1b (\#09-271, Millipore). Signals were visualized with immunoglobulin coupled to horseradish peroxidase, by use of the enhanced chemiluminescence (ECL Revel Blot Plus, Ozyme, Montigny le Bretonneux, France) and the Fusion FX7 chemoluminescence System (Thermo Fisher Scientific, Illkirch, France). The membranes were then reprobed using a mouse mAb directed against total Rac1 (\#05-389, Millipore). The autoradiographic signals were anayzed using the ImageJ software.

\section{Histological and immunohistological analysis}

Intestinal tissues -fixed in formalin either as flat segments or as "Swiss rolls" encompassing the full-length organ- were paraffin-embedded, cut into 4-um sections and stained with either hematoxylin-phloxine-saffron (HPS) or with Periodic acidSchiff/Alcian blue (PAS+BA) to detect the presence of neutral (pink) and acidic (blue) mucins respectively.

For immunohistochemistry the sections were immunolabelled with rabbit polyclonal anti-Ki67 antibody (1/50; \#RMAB004, Clinisciences, Nanterre, France), mouse monoclonal anti-BrdU antibody (1/750; \#B8434, Sigma-Aldrich), anti- $\beta$-catenin (1/800; \#610154, Transduction Laboratories, BD Biosciences, Le Pont de Claix, France), or monoclonal rabbit anti-phospho Histone $\operatorname{H2AX}(1 / 250$; \#9718 Cell Signaling, Ozyme) using a detection kit (\#DS9800, Bond Polymer Refine detection; Leica Microsystems, Nanterre, France). Substitution of the primary antibody with PBS was used as a negative control. 
To visualize ROS production, colonic tissue was open up along the anteroposterior axis, laid on Bristol board and incubated in phenol red free MEM supplemented with $30 \mu \mathrm{M}$ dihydroethidium (Molecular Probes, Thermo Scientific) for $30 \mathrm{~min}$ at $37^{\circ} \mathrm{C}$. After extensive washing in MEM, intestinal samples were snap frozen in liquid nitrogen and cryosectioned, and analyzed with a Zeiss 710 upright confocal microscope.

\section{Quantitation of cytokines using a multiplexed flow cytometric assay}

$\mathrm{BD}^{\mathrm{TM}}$ CBA Mouse Inflammation array Kit (BD Biosciences, Le Pont de Claix, France) was used to quantitatively measure Interleukin-6 (I6), Interleukin-10 (II10), Monocyte C-C Motif Chemokine Ligand 2 (CCL2)/ Monocyte Chemoattractant Protein-1(MCP1), Interferon- $\gamma$ (IFN- $\gamma$ ), Tumor Necrosis Factor (TNF- $\alpha$ ), and Interleukin-12p70 (II12p70) protein levels simultaneously in mouse colonic homogenates. This kit performance has been optimized for analysis of specific proteins in tissue.

Briefly, after extensive washing in PBS, intestinal samples were snap frozen in liquid nitrogen and cryopreserved. For preparation of tissue lysates for $\mathrm{BD}^{\mathrm{TM}} \mathrm{CBA}$ Mouse Inflammation array, intestinal tissue samples were disrupted in lysis buffer containing of protease inhibitor cocktail (P8340, Sigma Aldrich, St. Quentin Fallavier, France), using a Polytron apparatus (Kinematica, Thermo Fisher Scientific) and analyzed according to the manufacturer's instructions. For fluorescence detection via flow cytometry the mouse inflammation standards were reconstituted and serially diluted immediately before use. The standards and the test samples completed with capture beads and the PE detection reagent were incubated for 2 hours at room temperature in dark. After washing the samples were acquired on the flow cytometer (BD 
FACSCanto $^{\mathrm{TM}}$ II, BD Biosciences, Le Pont de Claix, France). The data analyses were processed using FCAP Array software (bdbiosciences.com/cbasetup).

\section{Apoptosis assay}

Cellular apoptosis was investigated using Click-iT ${ }^{\text {тм }}$ Plus TUNEL Assay for in situ apoptosis detection with Alexa Fluor ${ }^{\mathrm{TM}}$ dyes according to the recommendations of the manufacturer (Thermo Fisher Scientific).

Briefly, Click-iT ${ }^{\mathrm{TM}}$ Plus TUNEL Assay detects apoptotic cells from formalin-fixed, paraffin embedded (FFPE) tissue samples. These assays utilize EdUTP (a dUTP modified with a small, bio-orthogonal alkyne moiety), which is incorporated at the 3'$\mathrm{OH}$ ends of fragmented DNA by the TdT enzyme. Detection is based on a click reaction, a copper catalyzed covalent reaction between an Alexa Fluor ${ }^{\mathrm{TM}}$ picolyl azide dye and an alkyne. FFPE sections of intestine from wild-type and Rac1b transgenic mice, untreated, treated with DSS (acute phase of inflammation) or subjected to AOM/DSS -induced carcinogenesis, were processed with the Click-iT' Plus TUNEL assay/ Alexa Fluor ${ }^{\mathrm{TM}} 594$ dye (red) to detect DNA fragmentation in situ. After the TUNEL reaction, cells were counterstained with DAPI. The mild reaction conditions for the Click-iT' ${ }^{\mathrm{TM}}$ Plus TUNEL assays have been demonstrated to preserve cell morphology. The incorporation of the thymidine analogue 5-ethynyl-20deoxyuridine (EdU) in DNA was analyzed by fluorescence microscopy.

\section{Tissue morphometry}

Intestinal villi follow an anteroposterior size gradient. To avoid introducing bias related to the intestinal segment, villous height was measured on duodenal histological 
sections stained with hematoxylin eosin, using a Digital Microimaging Leica DMD 108 Device (Leica Microsystems, Nanterre, France). Similarly, the depth of colonic crypts was assessed in the distal colon. At least 15 well orientated crypts or villi per section were analyzed.

The histological grading of colitis was performed along the proximal, transverse and distal colon. The distal colon and at a lower extend transverse were more particularly affected, with extensive leukocyte and neutrophil infiltrations. We quantified, on the one hand, areas of goblet cell depletion, epithelial damage, mucosal erosion, ulceration, crypt abscesses, and, on the other, areas of regeneration, including monolayer of epithelial cells and aberrant crypt architecture with hyperplasia, using the Leica DMD 108 Device. Histological scoring was performed blindly by a histologist expert in intestinal inflammation (T.L.). Results were expressed as the percentage of length of tissue lesions or tissue repair referred to colon length.

Proliferative variables index were assessed by 2 of the authors (E.C. and L.K.) on coded specimens, examiners being unaware of their origin. BrdU and Ki67 labeled cells were recognizable by the brown pigment overlying their nuclei counterstained with Mayer's hemalum and examined using the Leica DMD 108 Device. Welloriented crypts with the lumen visible from the bottom to the mucosal surface and with a single layer of cells along each crypt column were selected for quantification. For each colonic segment, the percentage of labeled epithelial cells were quantified in 15-hemicrypt columns distributed all along the longitudinal tissue sections. To appreciate the spatial distribution of BrdU labeled cells within the mucosa, their position in the crypt was recorded.

For measurement of epithelial cell migration, each animal received a pulse of BrdU $20 \mathrm{~h}$ prior to sacrifice. The position location of the outer most BrdU-positive intestinal 
epithelial cells in along the villus (cellmax) and the villus height were measured using the Leica DMD 108 Device. At least 20 well-oriented and full-length villi along duodenum and the first third of jejunum from 7 control and 6 villin-Cre-/ LSLRac1bfloxflox mice were analyzed. Histomorphological evaluations were performed by three morphologically experienced investigators (E.C, L.K. and T.L.).

\section{Supplementary results}

The infiltration of colonic tissue by immune cells in control and villin-Cre LSLRac $1 b^{\text {floxfllox }}$ mice during the course of DSS challenge and recovery was assessed by measuring selective markers by RT-qPCR (Supplementary Figure 3). FoxP3 transcripts expressed by Treg raised 10 and 14 fold in control and Rac1b transgenic animals during the acute phase and remained sustained during the recovery. DSSinduced colitis was associated with the infiltration of CD8 positive cells in wild-type and Rac1b transgenic animals (3.8 and 2.7 fold increase in CD8 mRNA levels in wildtype and villin-Cre LSL-Rac1 $b^{\text {flox/flox }}$ animals, respectively), with an earlier normalization in villin-Cre LSL-Rac1bfloxfllox mice (2 fold vs. 2.9 in wild-type mice). In contrast, CD11b/ ITGAM a marker of leucocytes cells, and Arginase-1 expressed by M2-polarized macrophages -involved in tissue repair- were early and transiently induced after DSS treatment in villin-Cre LSL-Rac1bfloxfllox mice (5.5 fold for CD11b, 8.9 fold for Arg 1 at day 7 , and 3.2 and 3.6 fold at day 12, respectively) whereas this induction was delayed in wild-type animals (2.6 and 4 fold for CD11b and Arg1 at day 7 , and 4 and 25 fold at day 12). These observations indicate that leucocytes and M2macrophages are more quickly mobilized in villin-Cre LSL-Rac1bfloxflox mice during inflammatory process. The investigation on the accumulation of a series of 
inflammatory cytokines, revealed the strong induction of the transcripts encoding the pro-inflammatory cytokines IFN- $\gamma$, TNF- $\alpha$ and CXCL2/MIP2- $\alpha$ in both the control and villin-Cre LSL-Rac1bfloxflox animals (26 vs. 11 fold for IFN- $\gamma ; 7$ vs. 6.7 fold for TNF- $\alpha$ and 19 vs. 17.5 fold for MIP2- $\alpha$ on day 7 , respectively) with an earlier normalization one week after DSS treatment (day 12) in the Rac1b transgenic mice ( 5 vs. 3 fold; 3.3 vs. 2.2 fold and 15 vs. 7 fold, respectively). Such differential response was less pronounced or absent for CXCL1/ KC, 116 and CCL2/MCP1. Interestingly, the kinetic of expression of the anti-inflammatory cytokines II10 and TGF- $\beta$ was hastened in villin-Cre LSL-Rac1 bfloxflox animals with an earlier normalization 7 days after DSS treatment (3.8 and 5 fold increase for II10 on day 7 and day 12 in control vs. 7.3 and 3.5 fold in Rac1b mice; 2 and 2.6 fold vs. 2.9 and 1.6 fold for TGF- $\beta$ ). Thus, this immune response was in line with the improved tissue repair evidenced after DSSinduced tissue injury in villin-Cre LSL-Rac1bfloxflox animals. At protein levels, we measured a 4.2 and 3.2 fold-increase in TNF- $\alpha$ accumulation in DSS treated wildtype and Rac1b transgenic mice compared to untreated groups, a 13.8 and 7.1 foldincrease for MCP1, and 102 and 76 fold-increase for 116 (Supplementary Figure 4)

\section{Supplementary References}

1 Zhou C, Licciulli S, Avila JL, Cho M, Troutman S, Jiang P et al. The Rac1 splice form Rac1b promotes K-ras-induced lung tumorigenesis. Oncogene 2013; 32 : 903-909.

2 Marjou El F, Janssen K-P, Hung-Junn Chang B, Li M, Hindie VR, Chan L et al. Tissue-specific and inducible Cre-mediated recombination in the gut epithelium. 
Genesis 2004; 39: 186-193.

3 Droy-Dupre L, Vallee M, Bossard C, Laboisse CL, Jarry A. A multiparametric approach to monitor the effects of -secretase inhibition along the whole intestinal tract. Disease Models \& Mechanisms 2011; 5: 107-114.

4 Mathieu J, Mammar S, Eto B. Automated measurement of intestinal mucosa electrical parameters using a new digital clamp. Methods Find Exp Clin Pharmacol 2008; 30: 591-598.

5 Mamadou G, Charrueau C, Dairou J, Limas Nzouzi N, Eto B, Ponchel G. Increased intestinal permeation and modulation of presystemic metabolism of resveratrol formulated into self-emulsifying drug delivery systems. Int J Pharm 2017; 521: 150-155.

\section{Legends to supplementary Figures}

Supplementary Figure 1. Accumulation of the transcripts of LGR5 and cyclin D1 in intestinal epithelial cells isolated from villin-Cre LSL-Rac1 $b^{\text {flox/lox }}$ and wild-type mice.

The accumulation of the transcripts encoding Lgr5 and cyclin D1 in epithelial cells isolated from the top and bottom of colonic crypts (A); and in the jejunum (B) and the ileum (C) from wild-type and villin-Cre LSL-Rac1bfloxflox animals was quantified by RT-qPCR. The upper panels show the corresponding colonic crypt preparations and histological sections of the small intestine. Scale bar: $100 \mu \mathrm{m}$.

Supplementary Figure 2. Evaluation of apoptosis in the small intestine and in the colon from villin-Cre LSL-Rac1bflox/flox and wild-type mice. 
Small intestine and colon from wild-type and villin-Cre LSL-Rac1 $b^{\text {floxflox }}$ mice were swiss rolled, fixed, and the corresponding FFPE sections were subjected to TUNEL assay using the Click-iT ${ }^{\mathrm{TM}}$ Plus TUNEL Assay for in situ apoptosis detection with Alexa Fluor 594 (Red). The cell nuclei were counterstained with DAPI. Scale bar: $100 \mu \mathrm{m}$.

Supplementary Figure 3. Evaluation of immune cell infiltration and cytokine expression in the colon from villin-Cre LSL-Rac1bflox/flox and wild-type mice during the acute phase and the resolution phase of DSS-induced colitis.

A) The accumulation of the CD8, FoxP3, CD11b and Arg1 transcripts, selectively expressed by CD8 T cells, T- regulatory / suppressor- T cells, leucocytes and M2 polarized macrophages was investigated in distal colon from control wild-type and villin-Cre LSL-Rac1bfloxfllox mice, or during the acute and the resolution phase of DSSinduced colitis. Results standardized with the value measured in the distal colon from untreated wild-type animals, set as reference, are expressed as $\log _{2}$ scale, and are the mean of RT-qPCR performed on RNA extracted from 5-6 wild-type and 6 villinCre LSL-Rac1 bfloxfllox mice. Differences were evaluated by ANOVA followed by Tukey's post hoc test. * Significantly different from untreated wild-type animals at * $p<0.05$, and ${ }^{*}{ }^{*} p<0.001$, respectively.

B) The accumulation of the transcripts encoding the pro-inflammatory IFN- $\gamma$, TNF- $\alpha$, II6, CXCL1/KC, CXCL2/MIP2 $\alpha$ and CCL2/MCP1, and the anti-inflammatory II10 and TGF- $\beta$ cytokines was evaluated as described above. Differences were evaluated by ANOVA followed by Tukey's post hoc test. * Significantly different from untreated wild-type animals at ${ }^{*} p<0.05$, and ${ }^{*} p<0.001$, respectively. 
Supplementary Figure 4. Evaluation of the pattern of proinflammatory cytokines in untreated villin-Cre LSL-Rac1bfloxflox and wild-type mice and during the acute phase of DSS -induced inflammation.

Frozen samples of distal colon from villin-Cre LSL-Rac1bfloxfllox and wild-type mice untreated $(n=6)$ or during the acute phase of DSS -induced inflammation $(n=5)$ were homogenized and subjected to the multiplexed flow cytometric assay BD ${ }^{\mathrm{TM}} \mathrm{CBA}$ Mouse Inflammation array Kit. A significant increase in TNF- $\alpha$, CCL2/ MCP1 and II6 was observed during the acute phase of inflammation as compared with untreated groups (** $p<0.001)$, in contrast interferon- $\gamma, \| 12$ and II10 were not detected.

Supplementary Figure 5. DSS-induced acute colitis triggers phospho-H2AX $(\gamma \mathrm{H} 2 \mathrm{AX})$ expression in the colonic mucosa villin-Cre LSL-Rac1 $\mathrm{b}^{\text {flox/flox }}$ mice.

Histological analysis indicates that under physiological conditions the number of $\gamma \mathrm{H} 2 \mathrm{AX}$ positive cells is comparable in wild-type and Rac1b transgenic mice. DSS treatment induced a marked increased in $\gamma \mathrm{H} 2 \mathrm{AX}$ positive cells (red arrows) in colonic mucosa of DSS-treated villin-Cre LSL-Rac1 bfloxflox mice. Scale bar: $100 \mu \mathrm{m}$.

Supplementary Figure 6. Apoptosis detection in the colonic mucosa from villinCre LSL-Rac1bflox/flox and wild-type mice during the acute phase of DSS induced inflammation.

Formalin-fixed paraffin-embedded colon sections from DSS treated mice were analyzed using the Click-iT ${ }^{\mathrm{TM}}$ Plus TUNEL assay with the Alexa Fluor ${ }^{\mathrm{TM}} 594$ dye (red) to detect the DNA fragmentation in apoptotic colonic epithelial cells. Nuclei were counterstained with DAPI. White arrows display some apoptotic colonic epithelial cells. Apoptosis is limited to sparse isolated epithelial cells and few colonic glands. 
No marked change could be evidenced between the wild-type and the Rac1b transgenic mice. Scale bar: $100 \mu \mathrm{m}$.

\section{Supplementary Figure 7. Evaluation of apoptosis in AOM/ DSS -induced colorectal tumors from villin-Cre LSL-Rac1bflox/lox and wild-type mice.}

Formalin-fixed paraffin-embedded colon sections from AOM/DSS treated wild-type (left panels) and villin-Cre LSL-Rac1bfloxfliox mice (middle panels) were analyzed using the Click-iT ${ }^{\mathrm{TM}}$ Plus TUNEL assay with the Alexa Fluor ${ }^{\text {TM }} 594$ dye (red) to detect the DNA fragmentation in apoptotic intestinal cells. Nuclei were counterstained with DAPI. White arrows display some apoptotic colonic tumor cells. Right panels : enlargement of the middle panels. There is no obvious change in the level of apoptosis in colonic tumors from wild-type and Rac1b transgenic mice. Scale bar: $100 \mu \mathrm{m}$.

Supplementary Figure 8. Colitis-induced rectal prolapse in aged II10-/- mice.

Rectal prolapse from 30 weeks old $1110^{-/}$mouse showed a strong accumulation of CXCL2/MIP2 $\alpha$ and Rac1b transcripts as compared to distal colon. Histological analysis of rectal prolapse revealed a high infiltration of immune cells. Hematoxylin phloxine saffron staining (HPS); Periodic Acid Schiff, alcian blue staing (PAS+BA). Scale bar: $1 \mathrm{~mm}$. 

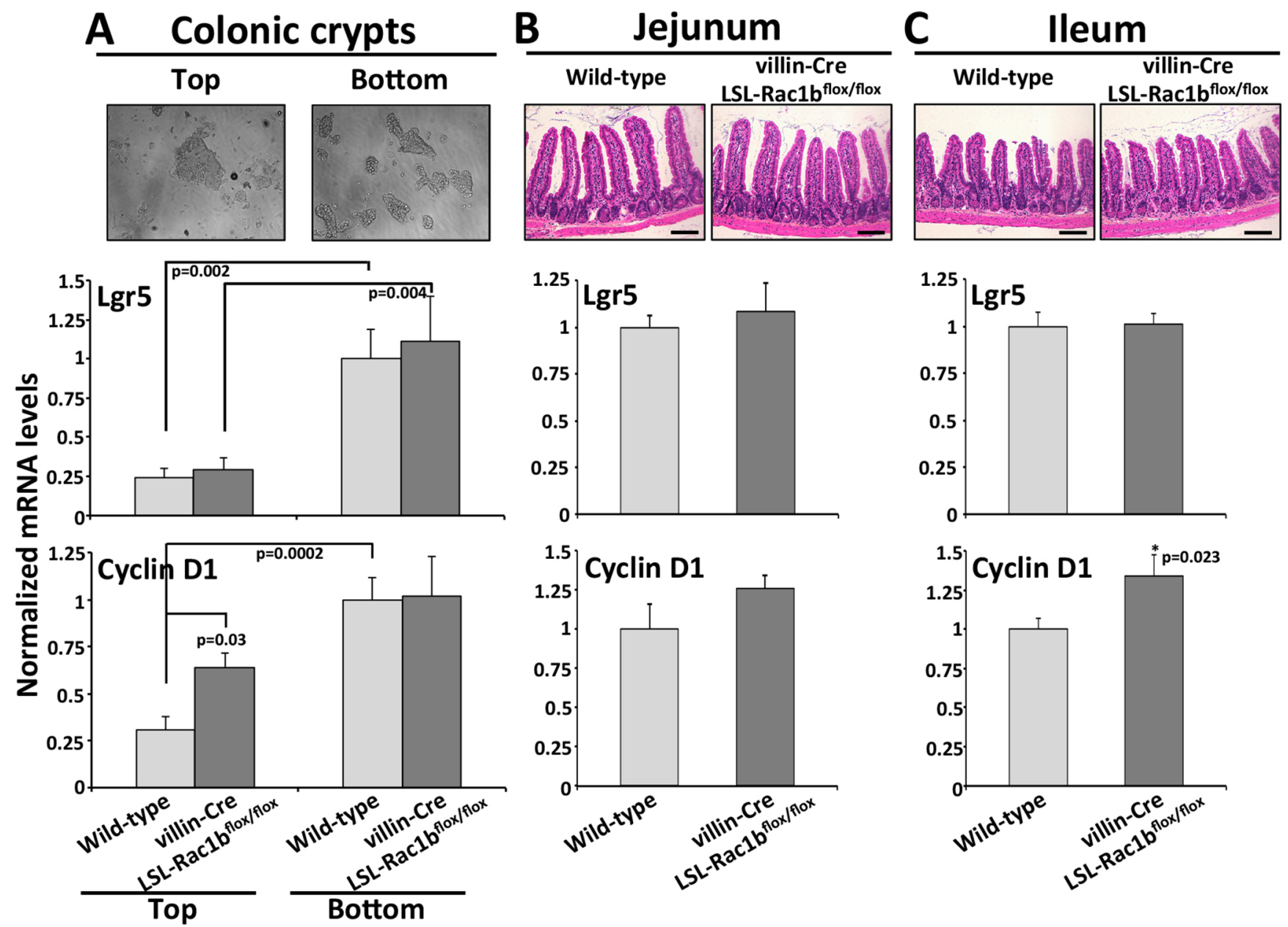

Supplementary Figure 1 
wild-type

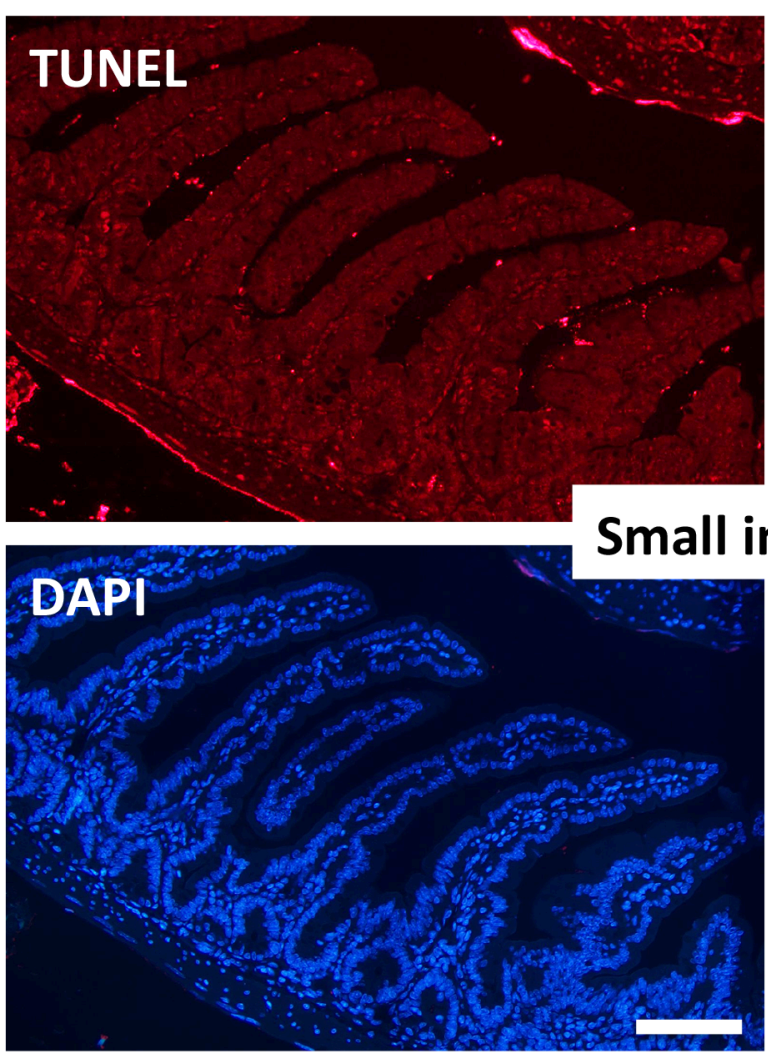

villin-Cre LSL-Rac1b flox/flox
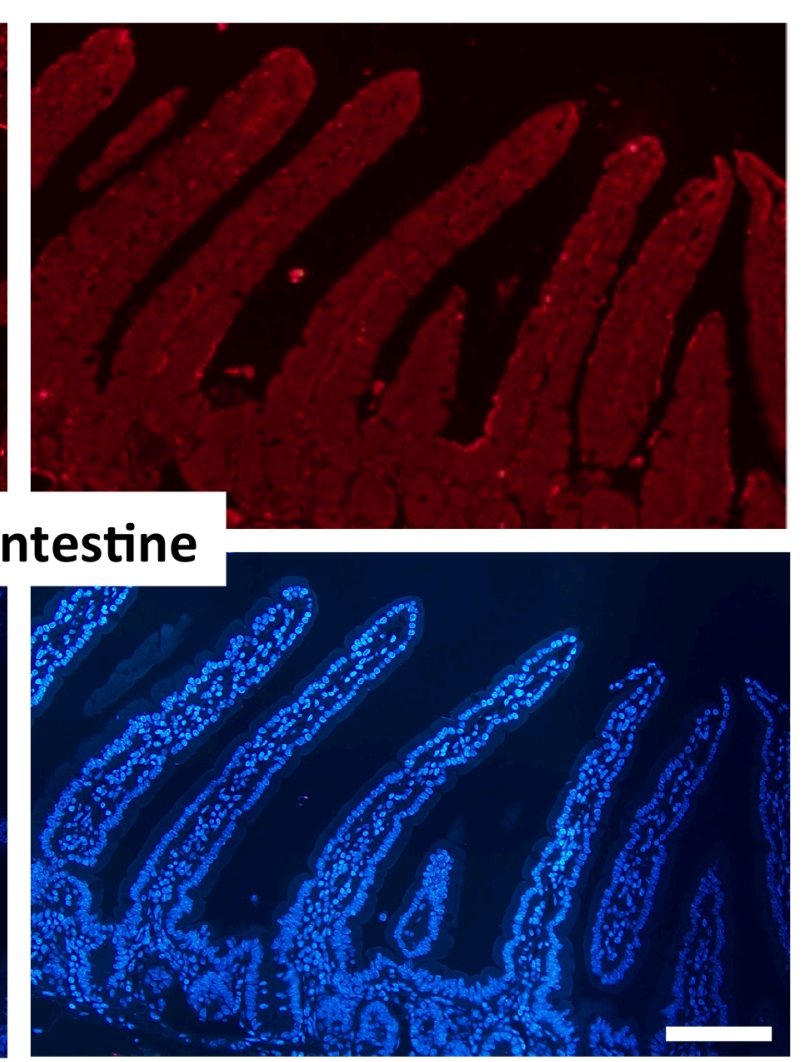

TUNEL

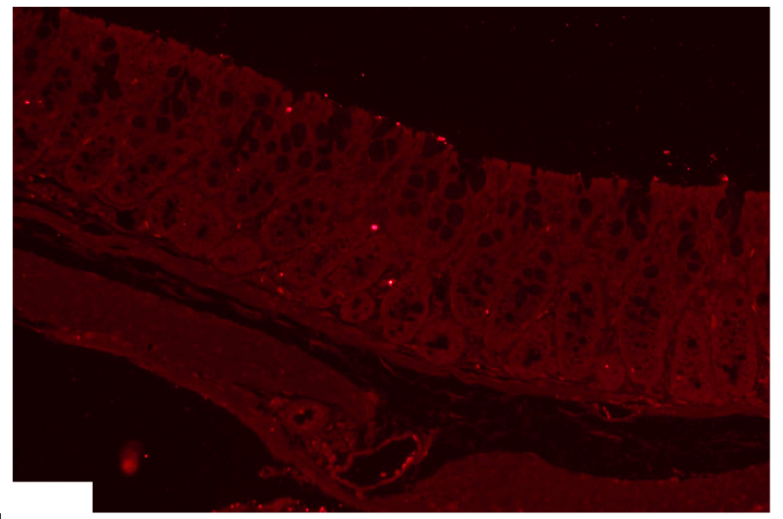

\section{Colon}

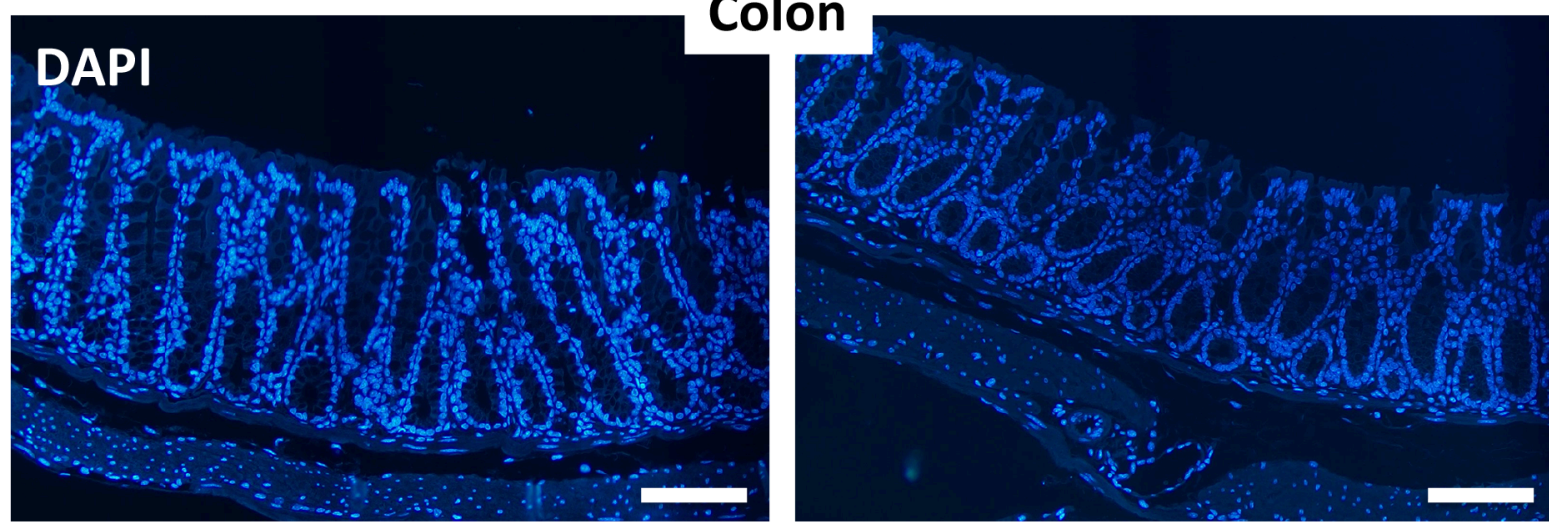

Supplementary Figure 2 

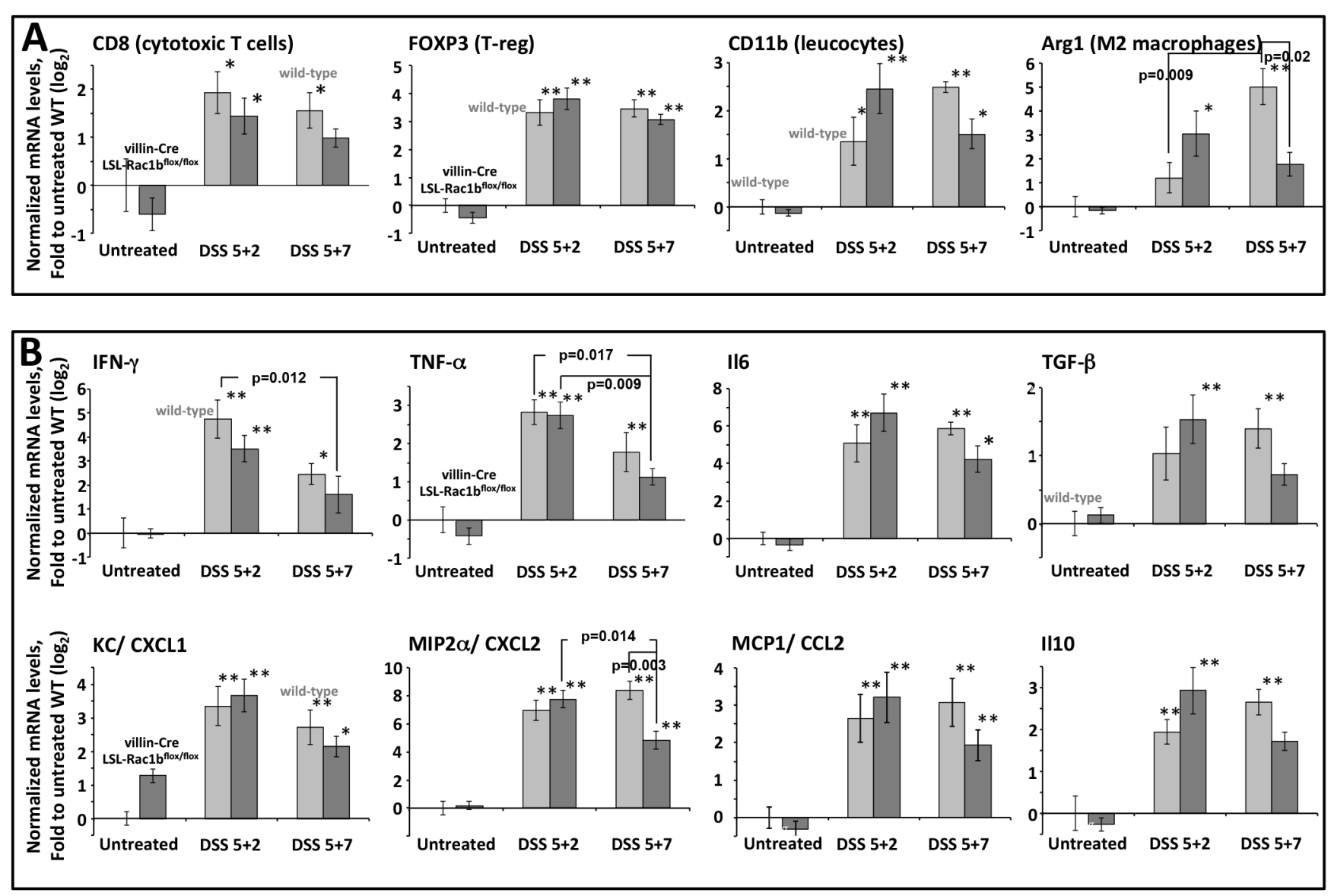

Supplementary Figure 3 

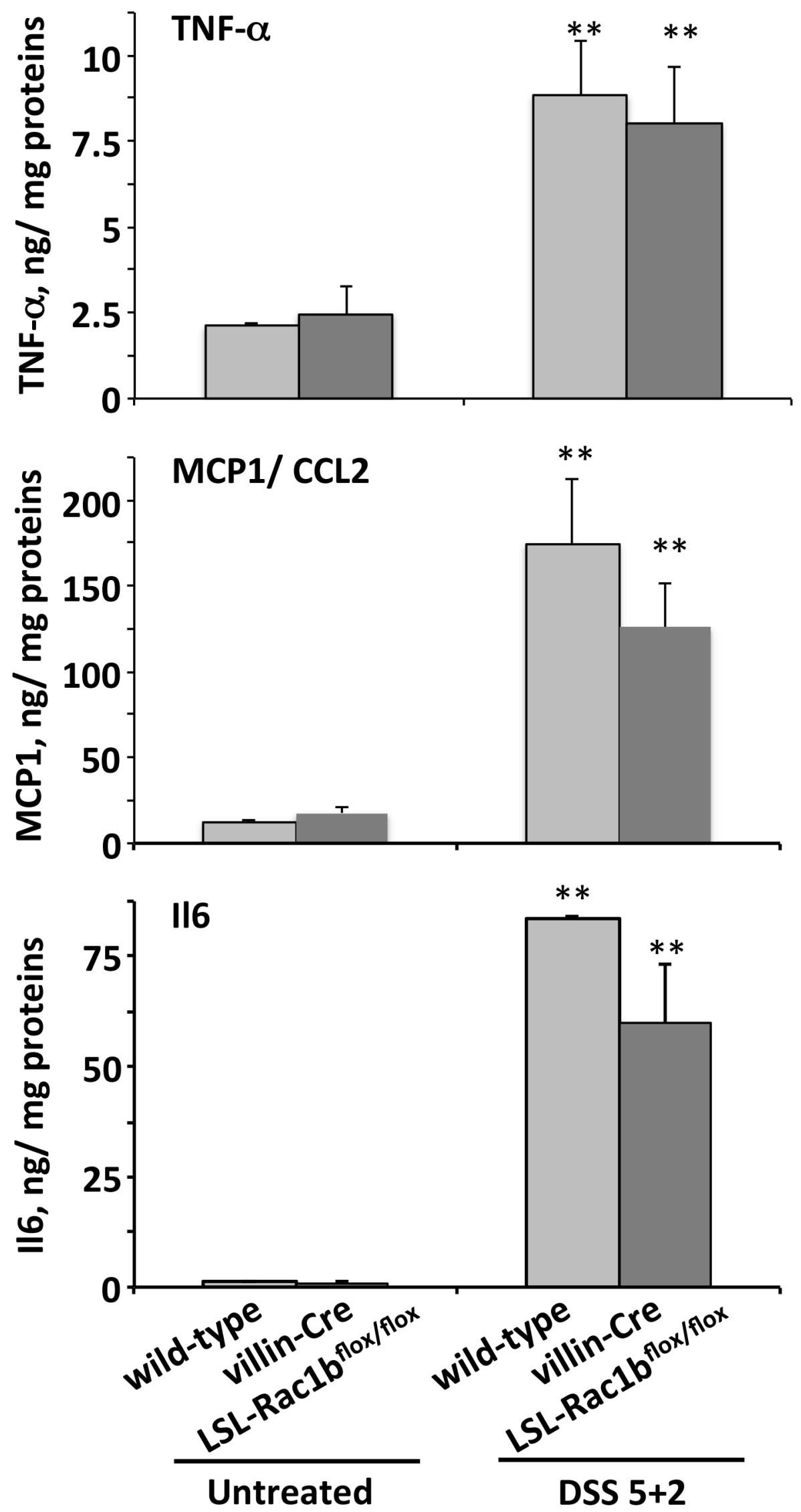

Supplementary Figure 4 

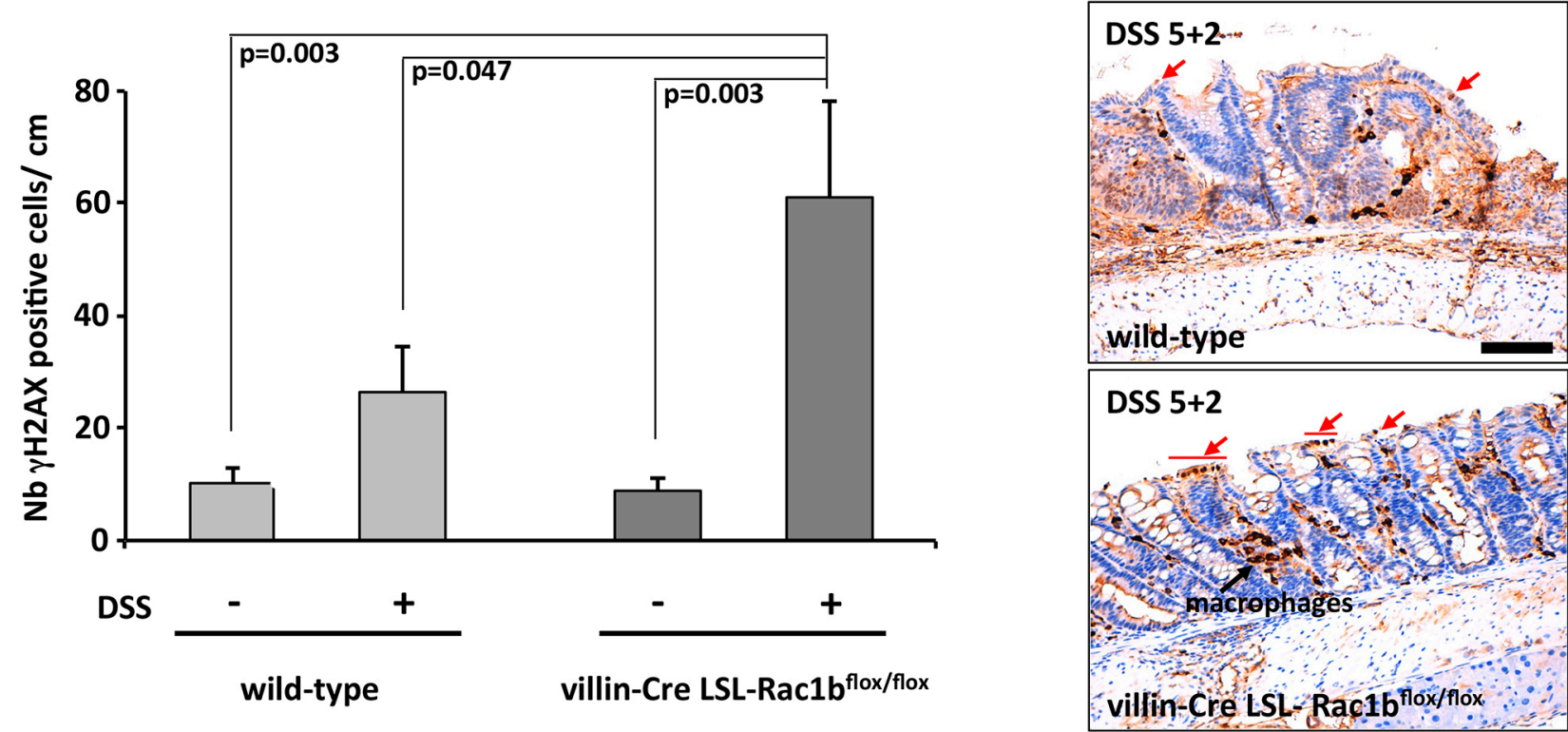

Supplementary Figure 5 
wild-type
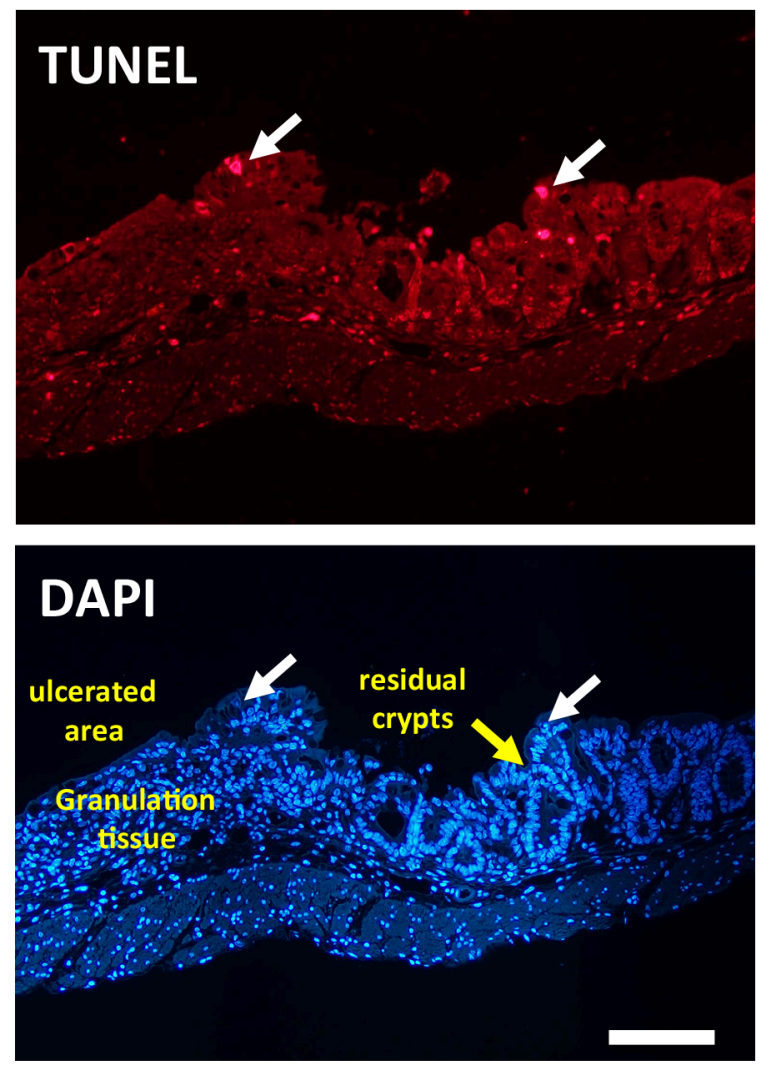

TUNEL
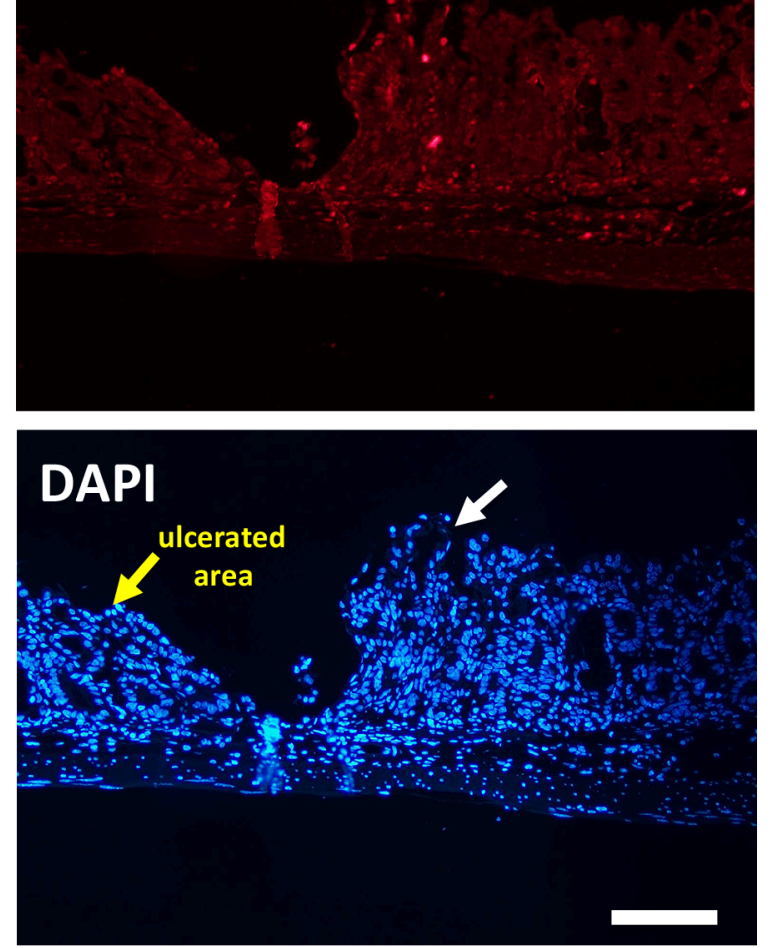

villin-Cre LSL-Rac1b flox/flox
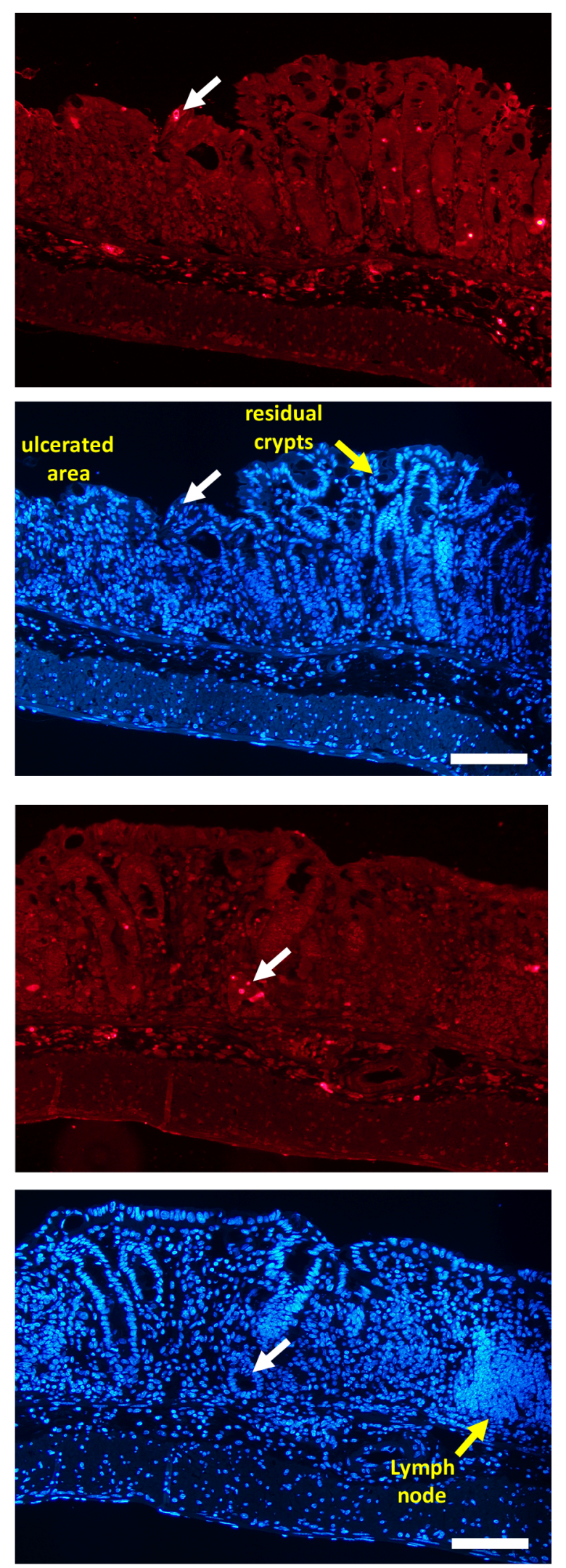

Supplementary Figure 6 


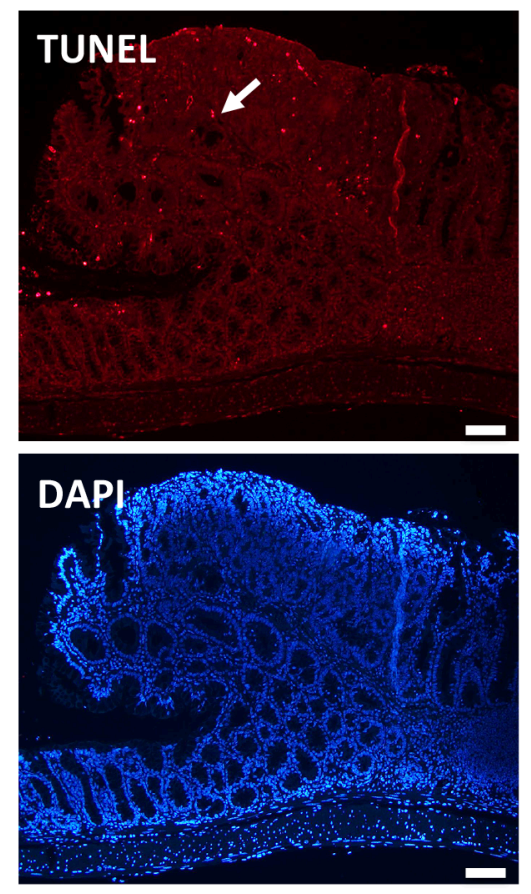

wild-type
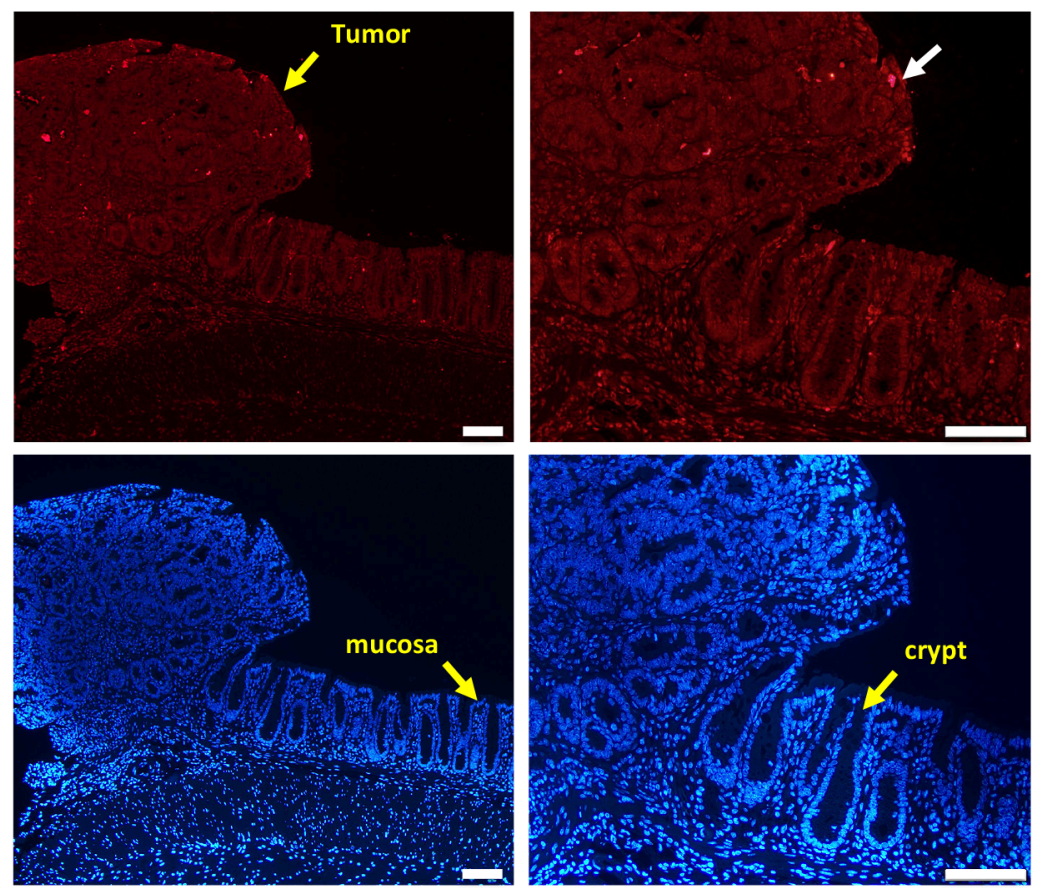

villin-Cre LSL-Rac1b $b^{\text {flox/flox }}$

Supplementary Figure 7 


\section{Rectal prolapse II10/- mice}
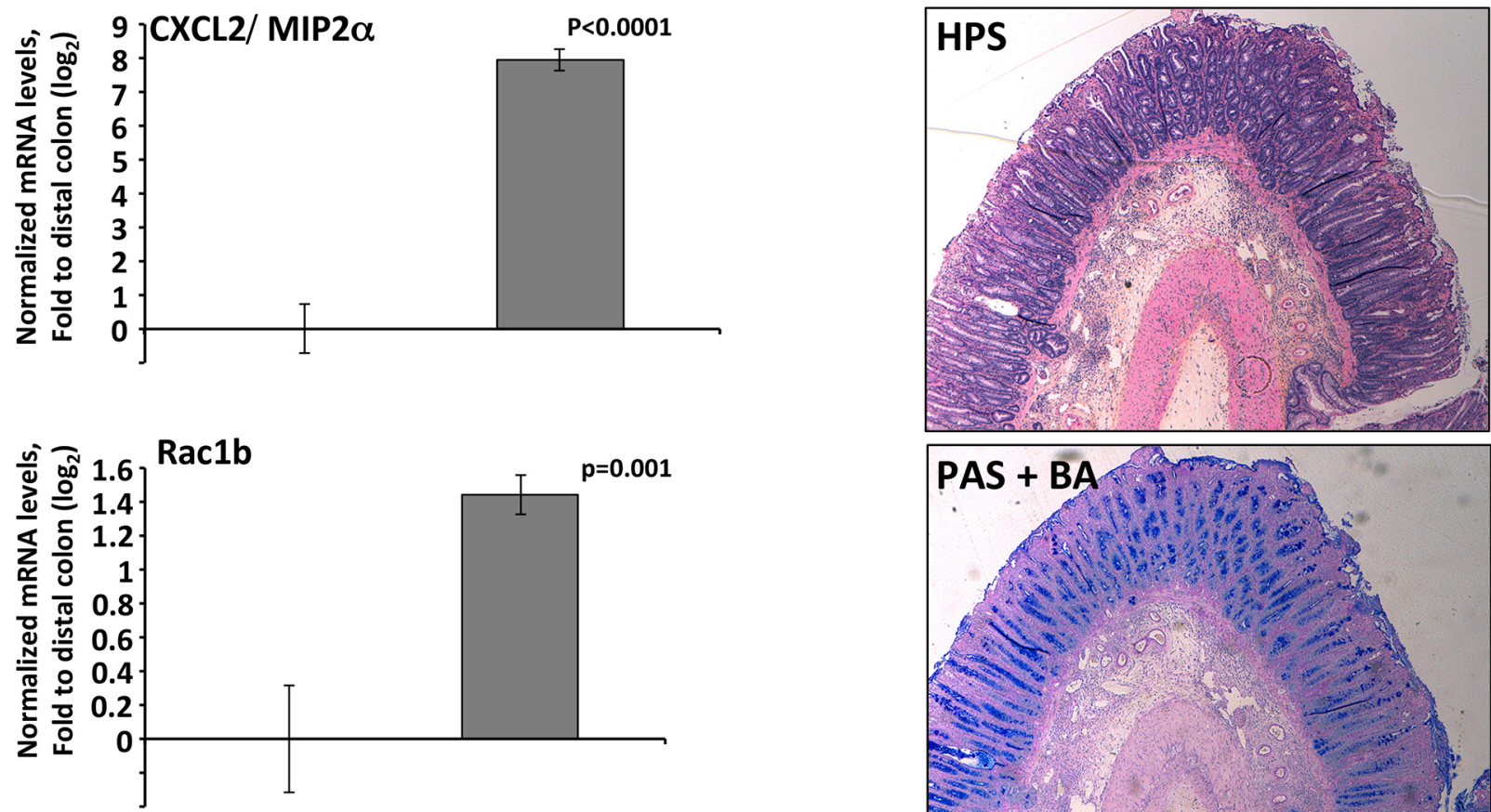

Distal colon Rectal Prolapse

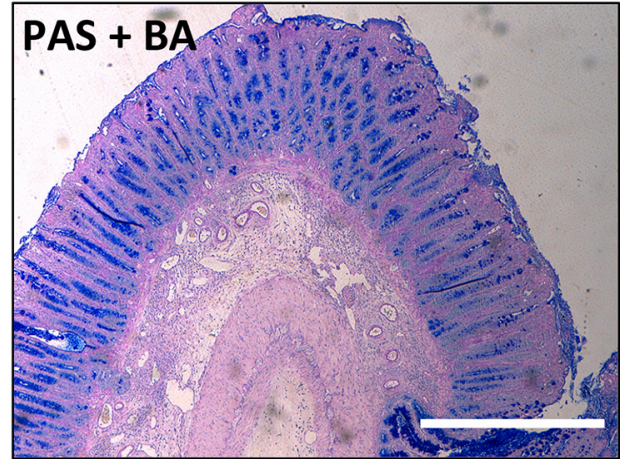

Supplementary Figure 8 


\section{Supplementary Table: Sequences of the primers used in this study}

\begin{tabular}{|c|c|c|c|c|}
\hline & Gane Name & NCA Acto8sion nb & Senes primer & Antisenge primer \\
\hline Arg1 & arginase 1 & NM 007482.3 & 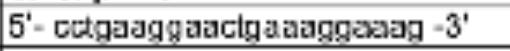 & 5' - thagcagalatgcopagagt - $3^{\prime}$ \\
\hline CCL2I MCP1 & C-C Motif Chemokine Ugand 2 & NM D11333.3 & 5'- evecencalgttgoctes -3 & 5'- gastcatettgetgatgaลtgsget - $\mathbf{3}^{\prime}$ \\
\hline CCND1 & cydin D1 & NM_007631.2 & 5'- tttctifccagagtcatcaagigt $-3^{\prime}$ & 5'- tgactccagaagggcttcas $-3^{\prime}$ \\
\hline CD11biltgam & Integrin alphs M & NM_001082960.1 & 5'- castagcoggucteggtgc -3 & 5'-gagocca gaggagaagtg $-3^{2}$ \\
\hline CDEa & CDS artigen, ajpha dhain & NM 001081110.2 & 5'- ctcacetgtgcaccetace $-3^{\prime}$ & $5^{\prime}$ - atcoggtcoccttcactg $-3^{\prime}$ \\
\hline CXCL1/ KC & chernokine (C)X-Cmotil) [gand 1 & NM_008176.3 & 5'- ggattcacctcaagaacatccagag -3' & 5 - caccettctactagcacagiggttg -3 \\
\hline $\mathrm{CXCL} 2 / \mathrm{MIP} 2 \alpha$ & chernokine [CX-Cmoili] [gand 2 & NM 009140.2 & 5' - aggctac iquggoctgltgtg -3' & 5'- cgtcacacicu agctclagat 3 \\
\hline Defa23 & detensin, alpha, 23 & NM_D010123[17.2 & 5' - gaggaatcgttgagag a tctggtatg -3' & 5' - ccatgttcagcgacagcagagc-3' \\
\hline Defe24 & defensin, alpha, 24 & NM_001024225.2 & 5'- gaggaatogittgageg atctggtatg $-3^{\prime}$ & 5'-ccatgttcagcgacegcegagc-3' \\
\hline FoxP3 & forkhead box P3 & NM 001199347.1 & $5^{\prime}$ - tcaggagcocaccagtaca $-3^{\prime}$ & 5'-tctgaagocagagtcagoaga $-3^{\prime}$ \\
\hline IFN-? & interferon gamma & NM_O013337.3 & 5'- cagcaacagcaaggegasa -3' & $5^{\prime}-$ ctpgacctgtgegttpltagac $-5^{\prime}$ \\
\hline IL10 & interleukin 10 & NM_010548.2 & 5'-cagagccacatgctcciaga $-3^{\prime}$ & $5^{\prime}$-gtccagctggtectttgttt $-3^{\prime}$ \\
\hline ILG & interleukin 8 & NM_031168.1 & 5'- gclaccasactgcatabaisagga -3' & 5' - ecagglagcliatggtaxtecaga -3 \\
\hline Ko & keratin 8 & NM_031170.2 & $5^{\prime}$ - copotccticatiqacaag $-3^{\circ}$ & $5^{\prime}$-gctgcaacaggctocactt -3' \\
\hline Larb & Icuene rien reocul convining G proten oxupled receptor 5 & NM 010195.2 & 5'- ctrcacteggtecagtect - $3^{\prime}$ & 5'- cagccagctascoantagote $-3^{\prime}$ \\
\hline Rac1 Total & FAS-related C3 batulinum subatrate 1 & NM_009007.2 & 5'- cctgcatcatttganaAtgtcog -3 & 5 - gatgataggagtattgggacagt $-3^{n}$ \\
\hline Racib & RAS-related C3 botulinum subatrate 1 & $\mathrm{X}, 1006504667.2$ & 5'- gggcaasgacaagcogattg $-3^{\prime}$ & $5^{\prime}$ - cggacattttcasatgaigcegg $-3^{\prime}$ \\
\hline $\mathrm{S} 14$ & ribosomal protainS14 & NM 020600.4 & 5'- cagapacceagacocctopa $-3^{\prime}$ & $5^{\prime}-$ atcttcatcccagagcogac - $3^{\prime}$ \\
\hline TGF- $\beta 1$ & transiorming growth factor, bets 1 & NM 011677.1 & 5'- tggageaseatgtggasete $=3$ & 5'-gteageagecggttacea -3' \\
\hline TNF- $\alpha$ & turnor necrosis factor & NM_013693.3 & 5'- aggctgeccegactacgt $-3^{*}$ & 5'-gacttctcctgatatgagatagcaaa -3' \\
\hline
\end{tabular}

